Article

\title{
Human Health Impacts of Aviation Biofuel Production: Exploring the Application of Different Life Cycle Impact Assessment (LCIA) Methods for Biofuel Supply Chains
}

\author{
Zhizhen Wang, Patricia Osseweijer and John A. Posada *iD \\ A Department of Biotechnology, Delft University of Technology, van der Maasweg 9, 2629 HZ Delft, \\ The Netherlands; z.wang-5@tudelft.nl (Z.W.); P.Osseweijer@tudelft.nl (P.O.) \\ * Correspondence: J.A.PosadaDuque@tudelft.nl
}

Received: 31 October 2019; Accepted: 3 January 2020; Published: 28 January 2020

\begin{abstract}
The life cycle human health $(\mathrm{HH})$ impacts related to aviation biofuels have been understood in a limited way. Life cycle impact assessment (LCIA) methods for assessing $\mathrm{HH}$ are often associated with a high level of uncertainty and a low level of consensus. As a result, it remains challenging to perform a robust assessment of $\mathrm{HH}$ impacts with a suitable LCIA method. This study aims to systematically compare six commonly used LCIA methods for quantifying HH impacts, in order to empirically understand the potential impacts of aviation biofuel production on $\mathrm{HH}$ and how the results are affected by the choice of methods. Three aviation biofuel production pathways based on different feedstocks (sugarcane, eucalyptus, and macauba) were analyzed and compared to fossil aviation biofuels, on the basis of a functional unit of $1 \mathrm{MJ}$ aviation fuel. The majority of the LCIA methods suggest that, in respect to midpoint impacts, macauba-based biofuel is associated with the lowest impacts and eucalyptus-based biofuel the highest; whereas at endpoint level, the results are more scattered. The LCIA methods agree that biomass conversion into aviation biofuel, H2 production, and feedstock cultivation are major contributors to life cycle $\mathrm{HH}$ impacts. Additionally, we provide a guideline for determining an appropriate method for assessing HH impacts.
\end{abstract}

Keywords: life cycle assessment; human health impacts; life cycle impacts assessment; LCIA method; sustainability assessment; aviation biofuel; human toxicity

\section{Introduction}

Biofuels play a significant role in sustainable development worldwide. As one of the most important and highly demanded alternative fuels, biofuels enable a more flexible energy mix and transition from a fossil-based economy to a biobased one. Among others, biofuel for aviation has gained growing interest in the recent decade. Major organizations in the aviation industry, the International Air Transport Association (IATA) and the International Civil Aviation Organization (ICAO), have committed to largely reduce emissions and achieve carbon neutral growth [1,2]. Previous studies have examined the greenhouse gas (GHG) emissions of aviation biofuel produced via different technological pathways [3-13]. These studies show that a considerable reduction in GHG emissions can be achieved by substituting fossil aviation fuel with biofuel, although the reduction percentage varies largely in the range of $41-104 \%$, due to differences in assessment scope, methodologies, and data inputs. However, it remains uncertain how aviation biofuel performs in terms of other sustainability-related impacts. A number of life cycle assessment (LCA) studies have pointed out biofuels could result in larger effects of acidification, eutrophication, and ecotoxicity than fossil fuels [14-18]. 
In comparison, the life cycle human health impacts related to biofuels are addressed and understood in a limited way. An important reason for this is the high level of uncertainty and low level of consensus in the modelling of human health impacts $[19,20]$. Several recent studies have focused on the life cycle assessment of human health impacts related to biofuel production. For instance, Weldu et al. [21] analyzed the human health impacts of electricity production from wood biomass in Alberta, Canada, and concluded that bioenergy pathways showed better performance in human health, but not in respiratory effects. Yang [17] investigated the life cycle human cancer-and non-cancer-effects of corn ethanol production in the U.S. The author showed that corn ethanol had higher potential non-cancer impacts than gasoline, however, both fuels led to similar potential cancer impacts. Galdos et al. [22] evaluated the human health impacts associated with Brazilian sugarcane ethanol production considering the phasing out of pre-harvesting burning. The results showed a clear improvement in human health related to the gradual termination of pre-harvesting burning. Other studies [14-17] included human health impacts in their LCA without further in-depth analysis, as most LCA studies underline GHG emission and energy related impacts [23].

So far, few studies have assessed the life cycle human health impacts related to aviation biofuel production. Furthermore, none of these studies specified how decisions were made regarding the selection of life cycle impact analysis (LCIA) methods for quantifying human health impacts. As recognized by several authors $[19,20,23]$, the results of LCIA studies heavily depend on methodological choices, timeframe, and data inputs. Ignoring this strong dependence makes comparison among different studies challenging. Moreover, assessment results may contradict each other when different LCIA methods are used. Therefore, it is imperative to understand how the selection of an LCIA method affects the results of assessment, especially the effects on human health. In this regard, Pizzol et al. [19] conducted a comparative analysis of nine different LCIA methods for assessing effects of metals on human health in an "imaginary" process. Significant differences were reported for the model structure, characterization factors ( $\mathrm{CFs}$ ), and assessment results. However, this comparison of LCIA methods was performed for a simple "imaginary" process, which (1) did not reflect the complexity of real-life case studies, and (2) did not resemble the features of a biofuel production supply chain. Additionally, almost all the LCIA methods analyzed in that study have experienced updates in terms of data sources or/and model structure.

The objective of this study is to provide an up-to-date comparison of different LCIA methods for quantifying the impacts on human health in the context of biofuel supply chains, taking aviation biofuel as an example in order to understand how results can be affected by the choice of method. Furthermore, we aim to understand the potential impacts of aviation biofuel production on human health, identify hotspots, and specify improvement opportunities. Hence, this study contributes to the overall understanding of the sustainability impacts assessment of aviation biofuel—especially the human health related aspects. First, the comparative analysis of LCIA methods empirically demonstrates their differences in assessing human health impacts as well as the consistency among various methods. Second, the analysis of human health impacts provides new insights into the life cycle impacts of aviation biofuel, broadening the discussion of biofuel's sustainability. As a result, a general guideline for selecting a LCIA method for assessing biofuels' impacts on human health is proposed.

\section{Materials and Methods}

\subsection{Overview of LCIA Methods Compared in This Study}

As described by Pizzol et al. [19], a number of LCIA methods have been developed to assess the impacts on human health, based on life cycle emissions. Most of the existing LCIA methods calculate impacts not only on human health, but also on other impact categories such as climate change and resource depletion. Unlike these methods, the USEtox 2 model—a relatively newly developed "scientific consensus" model [20,24]—only characterizes human toxicity and freshwater toxicity. 
Here we considered six commonly used LCIA methods for the comparative study based on three criteria: (i) the method contains a characterization model for impacts on human health, regardless of midpoint or endpoint level, (ii) the method has been used for LCA in peer-reviewed scientific articles, and (iii) the characterization model is transparent (i.e., at least the characterization factors ( $\mathrm{CFs}$ ) are published). Note that only the most recent version of each method is compared in this study. These six selected LCIA methods are: ReCiPe 2016 [25], USEtox 2 [20,24], IMPACT 2002+ [26], EDIP 2003 [27,28], CML-IA [29], and TRACI [30]. Note that the ILCD (International Reference Life Cycle Data System) method [31] proposed by the European Commission-Joint Research Centre is excluded from this comparative study. This is because ILCD only provides recommendations on the best practices in existing LCIA models and characterization factors, rather than developing a new model that is different from other methods. These methods are compared based on their fundamental features (later in this section) and their results (in Section 3) for different impact categories. Consensus and disagreement on the impacts on human health among these methods were analyzed. The comparison was conducted in an empirical case study of Brazilian aviation biofuel production.

The considered LCIA methods are different from each other in many aspects, such as the impact categories, the number of toxic chemicals included in the calculation, and the values of each characterization factor. As the focus of this study was not on model development, we concentrated on comparing the key differences in model basics: model structure (multimedia or single media, exposure pathways, and environmental compartments), impact categories, characterization factors, temporal and spatial scales, and how uncertainty is dealt with in each method.

In general, an LCIA model represents different environmental compartments that are taken into account and how substances move around, transport, and transform within and between them. The impacts on human health are modelled as shown in Equation (1):

$$
\mathrm{HH}=\sum(\mathrm{CFi} \times \mathrm{Mi})=\sum(\mathrm{IFi} \times \mathrm{EFi} \times \mathrm{Mi})
$$

where $\mathrm{HH}$ represents human health impact expressed at midpoint level or endpoint level, CF is the characterization factor that determines the potential impacts on human health of a substance released to a certain compartment (e.g., air, water, or soil), and $\mathrm{M}$ is the amount of a substance emitted to a certain compartment. CF can further be determined by the intake factor (denoted by IF) and effect factor (denoted by EF). IF reflects the fate and exposure pathway of a certain substance, meaning how the emitted substance disperses among compartments and the quantity of this substance reaching the human population (by inhalation, ingestion, or dermal exposure). EF quantifies the impacts on human health on the basis of per unit of intake of a certain substance. The fate, human exposure, and toxicity effect are generally modelled with matrix algebra-based calculations. Different LCIA methods use different approaches to determine their intake (fate and exposure) factor and effect factor, resulting in different sets of CFs. These factors are essentially where the major differences between different LCIA methods originate. The main differences concerning different human health LCIA models are summarized in Table 1. Here and hereinafter, the term "human health impacts" or "impacts on human health" refers to all impact pathways relevant to human health at midpoint and endpoint levels, while "human health" refers to the endpoint impact category: human health. 
Table 1. Main features of different LCIA methods ( $\sqrt{ }$ : the method considers the feature described; $\times$ : the method does not consider the feature described).

\begin{tabular}{|c|c|c|c|c|c|c|c|}
\hline \multicolumn{2}{|c|}{ Method } & USEtox2 & ReCiPe2016 & IMPACT2002+ & EDIP2003 & CML-IA & TRACI \\
\hline \multicolumn{2}{|c|}{ Reference } & {$[20,24,32]$} & {$[25,33]$} & {$[26,34]$} & {$[27,28]$} & [31] & {$[30,35]$} \\
\hline Model structure & Multimedia & $\sqrt{ }$ & $\sqrt{ }$ & $\sqrt{ }$ & $x$ & $\sqrt{ }$ & $\sqrt{ }$ \\
\hline \multirow{29}{*}{ Midpoint } & $\mathrm{HCT}^{\mathrm{a}}$ (cases) & $\sqrt{ }$ & $x$ & $x$ & $x$ & $x$ & $\sqrt{ }$ \\
\hline & $\mathrm{HNCT}^{\mathrm{b}}$ (cases) & $\sqrt{ }$ & $\times$ & $\times$ & $x$ & $\times$ & $\sqrt{ }$ \\
\hline & $\mathrm{HCT}^{\text {a }}$ (kg 1,4DCB-eq) & $x$ & $\sqrt{ }$ & $\times$ & $x$ & $\times$ & $x$ \\
\hline & $\mathrm{HNCT}^{\mathrm{b}}$ (kg 1,4DCB-eq) & $\times$ & $\sqrt{ }$ & $\times$ & $x$ & $\times$ & $x$ \\
\hline & $\mathrm{HCT}^{\mathrm{a}}\left(\mathrm{kg} \mathrm{C}_{2} \mathrm{H}_{3} \mathrm{Cl}-\mathrm{eq}\right)$ & $x$ & $x$ & $\sqrt{ }$ & $x$ & $x$ & $x$ \\
\hline & $\mathrm{HNCT}^{\mathrm{b}}\left(\mathrm{kg} \mathrm{C}_{2} \mathrm{H}_{3} \mathrm{Cl}\right.$-eq $)$ & $\times$ & $x$ & $\sqrt{ }$ & $x$ & $x$ & $x$ \\
\hline & $\mathrm{HT}^{\mathrm{c}}(\mathrm{kg} \mathrm{1,4DCB-eq)}$ & $x$ & $x$ & $x$ & $x$ & $\sqrt{ }$ & $x$ \\
\hline & $\mathrm{FPM}^{\mathrm{d}}\left(\mathrm{kg} \mathrm{PM}_{2.5}\right.$-eq) & $x$ & $\sqrt{ }$ & $\times$ & $x$ & $x$ & $x$ \\
\hline & $\mathrm{RI}^{\mathrm{e}}\left(\mathrm{kg} \mathrm{PM} 2.5^{-\mathrm{eq}}\right)$ & $x$ & $x$ & $\sqrt{ }$ & $x$ & $x$ & $x$ \\
\hline & $\mathrm{HHP}^{\mathrm{f}}\left(\mathrm{kg} \mathrm{PM}_{2.5}\right.$-eq $)$ & $\times$ & $x$ & $x$ & $x$ & $\times$ & $\sqrt{ }$ \\
\hline & $\mathrm{FPM}^{\mathrm{d}}\left(\mathrm{kg} \mathrm{PM}_{2.5}-\mathrm{eq}\right)$ & $x$ & $\sqrt{ }$ & $x$ & $x$ & $x$ & $x$ \\
\hline & POF $g\left(\mathrm{~kg} \mathrm{NO}_{\mathrm{x}}-\mathrm{eq}\right)$ & $x$ & $\sqrt{ }$ & $x$ & $x$ & $x$ & $x$ \\
\hline & $\mathrm{PO}^{\mathrm{h}}$ (kg Ethylene-eq) & $x$ & $\times$ & $\sqrt{ }$ & $x$ & $x$ & $x$ \\
\hline & $\operatorname{PSF}^{\mathrm{i}}\left(\mathrm{kg} \mathrm{O}_{3}-\mathrm{eq}\right)$ & $x$ & $x$ & $x$ & $x$ & $x$ & $\sqrt{ }$ \\
\hline & OLD $^{\text {j }}$ (kg CFC-11-eq) & $\times$ & $\sqrt{ }$ & $\sqrt{ }$ & $x$ & $x$ & $x$ \\
\hline & $\mathrm{IR}^{\mathrm{k}}$ (Bq Carbon-14-eq) & $\times$ & $x$ & $\sqrt{ }$ & $x$ & $x$ & $x$ \\
\hline & $\mathrm{IR}^{\mathrm{k}}(\mathrm{Bq}$ Co-60-eq) & $x$ & $\sqrt{ }$ & $x$ & $x$ & $x$ & $x$ \\
\hline & $\mathrm{GW}^{\mathrm{l}}\left(\mathrm{kg} \mathrm{CO} \mathrm{CO}_{2}\right.$-eq) & $\times$ & $\sqrt{ }$ & $\times$ & $\times$ & $\times$ & $\times$ \\
\hline & HTP m-air (person·yr) & $x$ & $x$ & $x$ & $\sqrt{ }$ & $x$ & $x$ \\
\hline & HTP $^{\mathrm{m}}$-water (person $\cdot y r$ ) & $x$ & $\times$ & $x$ & $\sqrt{ }$ & $x$ & $x$ \\
\hline & HTP ${ }^{m}$-soil (person·yr) & $x$ & $\times$ & $x$ & $\sqrt{ }$ & $x$ & $x$ \\
\hline & $\mathrm{HH}^{\mathrm{n}}(\mathrm{DALY})$ & $\sqrt{ }$ & $\sqrt{ }$ & $\sqrt{ }$ & $x$ & $x$ & $x$ \\
\hline & $\mathrm{CTU}_{\mathrm{h}}{ }^{\mathrm{o}}$ (cases/kg) & $\sqrt{ }$ & $x$ & $x$ & $x$ & $\times$ & $\sqrt{ }$ \\
\hline & $\mathrm{HTP}^{\mathrm{m}}$ (kg 1,4DCB-eq/kg) & $x$ & $\sqrt{ }$ & $x$ & $x$ & $\sqrt{ }$ & $x$ \\
\hline & HTP $^{m}$ (kg chloroethylene-eq $/ \mathrm{kg}$ ) & $x$ & $\times$ & $\sqrt{ }$ & $x$ & $x$ & $\times$ \\
\hline & RIP P $(\mathrm{kg} \mathrm{PM} 2.5-\mathrm{eq} / \mathrm{kg})$ & $\times$ & $\times$ & $\sqrt{ }$ & $x$ & $\times$ & $\times$ \\
\hline & PMFP q (kg PM 2.5 into air-eq $/ \mathrm{kg})$ & $x$ & $\sqrt{ }$ & $x$ & $x$ & $\times$ & $\sqrt{ }$ \\
\hline & $\mathrm{POP}^{\mathrm{r}}$ (kg Ethylene into air-eq/kg) & $x$ & $x$ & $\sqrt{ }$ & $x$ & $\times$ & $\sqrt{ }$ \\
\hline & $\mathrm{HOFP}^{\mathrm{s}}(\mathrm{kg} \mathrm{NO}$ into air-eq/kg) & $x$ & $\sqrt{ }$ & $\times$ & $x$ & $x$ & $x$ \\
\hline Midpoint & $\mathrm{SFP}^{\mathrm{t}}\left(\mathrm{kg} \mathrm{O}_{3}\right.$ into air-eq/kg) & $x$ & $x$ & $x$ & $x$ & $x$ & $\sqrt{ }$ \\
\hline
\end{tabular}


Table 1. Cont.

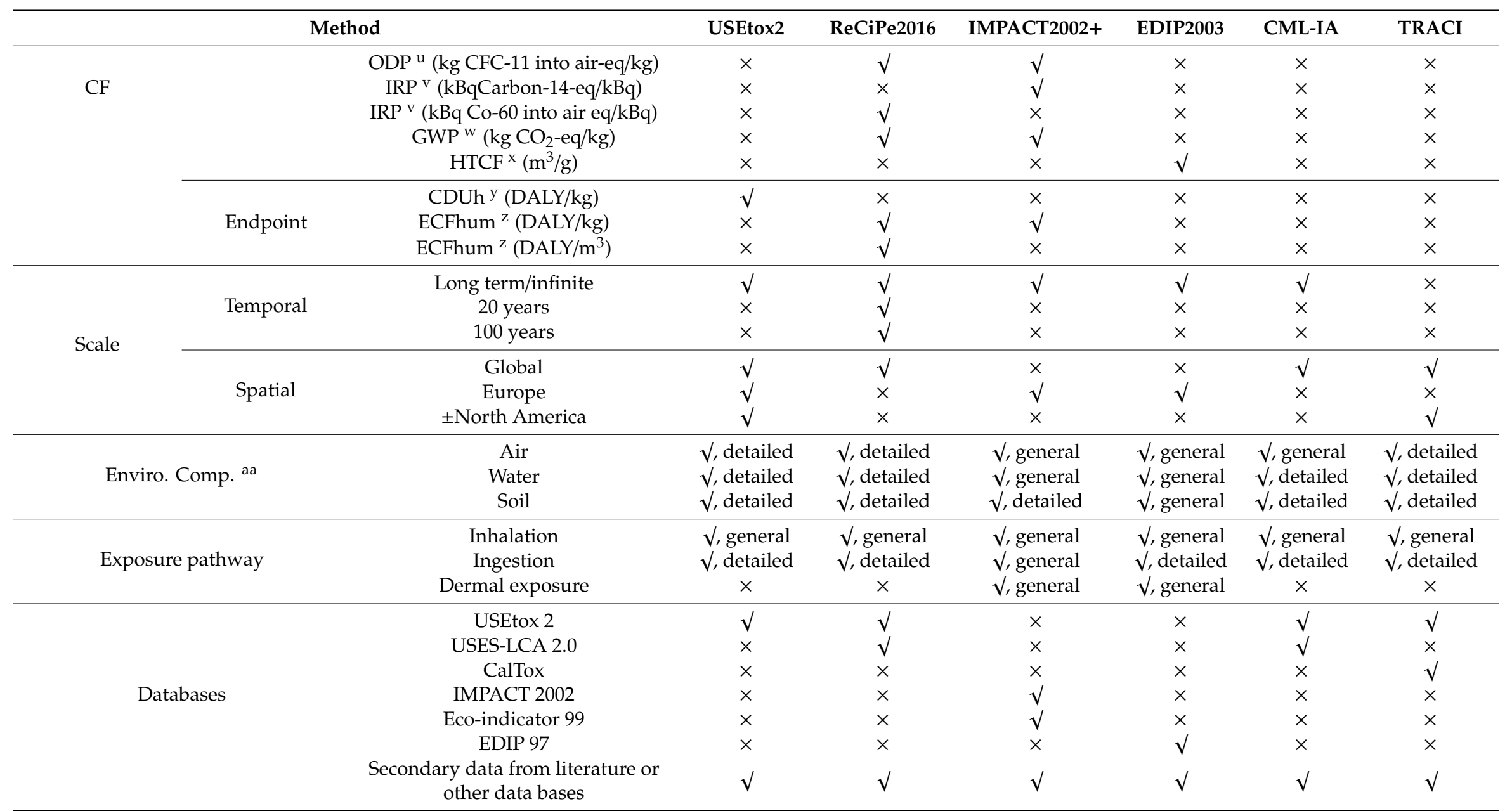

${ }^{a}$ HCT—human carcinogenic toxicity ${ }^{b}$ HNCT—human non-carcinogenic toxicity ${ }^{\mathrm{c}}$ HT—human toxicity ${ }^{\mathrm{d}}$ FPM—fine particular matter ${ }^{\mathrm{e}}$ RI—respiratory inorganics ${ }^{\mathrm{f}} \mathrm{HHP}-$ human health particulate ${ }^{\mathrm{g}} \mathrm{POF}-$ photochemical ozone formation ${ }^{\mathrm{h}} \mathrm{PO}-$ photochemical oxidation (also named "respiratory effects from organics") ${ }^{\mathrm{i}}$ PSF-photochemical smog formation ${ }^{\mathrm{i}}$ OLD—ozone layer depletion. ${ }^{k}$ IR-ionizing radiations ${ }^{1} \mathrm{GW}-$ global warming ${ }^{\mathrm{m}} \mathrm{HTP}-$ human toxicity potential ${ }^{\mathrm{n}} \mathrm{HH}-$ human health ${ }^{\mathrm{O}} \mathrm{CTU}-$ comparative toxic units $^{\mathrm{P}}$ RIP-respiratory inorganics potential 9 PMFP${ }^{u}$ ODP—ozone depleting potential ${ }^{v}$ IRP-ionizing radiation potential ${ }^{\mathrm{w}} \mathrm{GWP}$ - global warming potential ${ }^{\mathrm{x}} \mathrm{CDU}_{\mathrm{h}}$ - comparative damage units (human health characterization factor) ${ }^{\mathrm{y}}$ DCFhum — endpoint characterization factor for human health ${ }^{\mathrm{z}} \mathrm{HTCF}$ - human toxicity characterization factor aa Environmental compartment. 


\subsubsection{Impact Category}

USEtox 2, ReCiPe 2016, and IMPACT 2002+ express human health impacts at both midpoint level and endpoint level, although different impact categories and units are used in different methods. At endpoint level, disability adjusted life years (DALY) is the commonly used unit by these methods to measure impacts on human health $(\mathrm{HH})$. The categories of midpoint level impacts, on the other hand, are more diverse and vary from method to method. The midpoint impact categories of human carcinogenic toxicity (HCT) and human non-carcinogenic toxicity (HNCT) are covered by USEtox 2, ReCiPe 2016, IMPACT 2002+, and TRACI. Apart from that, ReCiPe 2016 and IMPACT 2002+ assess several additional midpoint impacts (as shown in Table 1), resulting in impacts on human health at the endpoint level through a damage pathway. Specifically, ReCiPe 2016 assesses fine particulate matter formation, photochemical ozone formation, ionizing radiation, and stratospheric ozone depletion, global warming, and water use, whereas IMPACT 2002+ evaluates respiratory inorganics, photochemical oxidation (equivalent to respiratory organics), ionizing radiations, ozone layer depletion, water withdrawal, and water consumption. TRACI is a midpoint assessment method, which expresses impacts on human health as human health particulate and photochemical smog formation, in addition to human carcinogenic and non-carcinogenic toxicity. CML-IA only provides the quantification of impacts on human health at midpoint level, expressed as Human Toxicity Potential (HTP). In addition, EDIP 2003 offers solely the midpoint characterization of human health impacts, expressed as Person Equivalents (PE).

It is worth noting that ReCiPe 2016, IMPACT 2002+ and TRACI all evaluate respiratory health impacts but expressed as differently named impact categories. However, taking a closer look at the definitions of these impacts, the "respiratory inorganics" in IMPACT 2002+, "fine particulate matter formation" in ReCiPe 2016, and "human health particulate" in TRACI are in fact similar to or equivalent, referring to the respiratory effects caused by fine particulate matter. Similarly, "respiratory organic" in IMPACT 2002+, "photochemical ozone formation" in ReCiPe 2016, and "photochemical smog formation" in TRACI all refer to the impact of photochemical reaction on human health.

\subsubsection{Model Structure and Inputs}

Most LCIA methods compared in this study use the multimedia model structure for capturing the fate of emissions. USEtox 2 [32] uses a multimedia box model at four spatial scales (i.e., indoor, urban, continental, and global) for calculating fate factors and exposure factors. The effect modelling is based on aggregated statistics for cancer and non-cancer effects. All model inputs are obtained from existing databases and peer reviewed literature. All the input data used in USEtox 2 have been evaluated for consistency and reliability [32]. ReCiPe 2016 [25] calculates the fate, exposure, and effect factors with the USES-LCA 2.0 multimedia fate, exposure, and effects model [35]. The determination of CFs is based on toxicity data from lab animals and human beings, the USEtox 2 organic and inorganic database [32], and the USES-LCA 2.0 substance database [35]. IMPACT 2002+ [26] uses a multimedia fate and multi-pathway exposure model. The effect factors are then determined with a dose-response slope. CFs are calculated based on other models including IMPACT 2002 [24] and Eco-indicator 99 [36]. CML-IA also uses the USES-LCA 2.0 multimedia model for calculating fate, exposure, and effect factors. The CFs are determined with substance databases of USES-LCA 2.0 [35] and USEtox 2 [32]. The midpoint method, TRACI, applies different models for characterizing different impacts on human health. TRACI [30,35] has replaced its previous CalTox model [37] with the USEtox model for characterizing human carcinogenic and non-carcinogenic toxicity. Additionally, human health particulate matter in TRACI is calculated based on the modelling of fate and exposure into intake fractions, which represent the ratio of the emitted substance expected to be inhaled, considering the U.S. locality. For calculating photochemical smog formation, the Maximum Incremental Reactivity (MIR) method [38,39] — developed specifically for the U.S. context—is used in TRACI. In EDIP 2003 [27,28], a different modelling approach-"some-fate modelling", according to EDIP—is used to account for the properties that are vital for substances' potential for human toxicity. This approach aims to incorporate 
these properties in the expression of CFs in a transparency way. The human toxicity impacts are modelled based on a fate-corrected human reference dose or concentration. The calculation of CFs is based on values provided in the previous version of the method, EDIP 97 [40,41], in addition to newly added spatial differentiated "exposure factors" for Europe concerning emissions to air via inhalation $[27,28]$. These site-dependent exposure factors offer the possibility to assess spatially differentiated variations in case of an increase in accumulated exposure $[27,28]$.

\subsubsection{Temporal and Spatial Scales}

In terms of the temporal scale of different methods, almost all methods consider only the default long-term or infinite time frame, except for ReCiPe 2016, which considers three different time spans: 20 years, 100 years, or infinite. With regard to the spatial scale, IMPACT 2002+ is Western Europe based. EDIP 2003 allows three different modes of evaluation: site-generic, site-dependent, and site-specific, where the latter two modes are only suitable for Europe, whereas the site-generic mode is global. USEtox 2 and CML-IA are global methods without detailed spatial resolution. TRACI used to be completely based on North American data. However, since it has adopted the USEtox model and substance database, the effect modelling of human carcinogenic and non-carcinogenic toxicity is now based on global data [35], while the assessment of human health particulate matter and photochemical smog formation remains American.

\subsubsection{Uncertainties}

Uncertainties are also handled differently by different methods. USEtox 2 addresses uncertainty by distinguishing two categories of CFs for human toxicity: "recommended" and "indicative". The "indicative" CFs are suggested with a higher level of uncertainty than the "recommended" CFs. LCA practitioners are advised to use the "indicative" CFs together with the "recommended" ones, as otherwise, the impacts of the substances with "indicative" CFs will be zero [32]. Accordingly, USEtox (r) represents the effects modelling using only "recommended" CFs whereas USEtox $(r+i)$ represents the effects modelling considering both "recommended" and "indicative" CFs. The ReCiPe 2016 method groups uncertainties stemming from different sources and different value choices into three different perspectives (i.e., individualist, hierarchist, and egalitarian) [25,33], based on the "Cultural Theory" proposed by Thompson et al. (1990). LCA practitioners are encouraged to consider all three perspectives for a sensitivity analysis on the outcomes [25]. The "individualist" perspective, denoted by ReCiPe 2016(I), is short-term interest oriented. It focuses on undisputed impact categories, and believes human adaptation is based on technological optimism. The "hierarchist" perspective, denoted by ReCiPe 2016(H), is based on scientific consensus in respect to the assessment time frame and the plausibility of impact mechanisms. The "egalitarian" perspective, denoted by ReCiPe 2016(E), considers the longest time frame and accounts for all impacts with available data [25]. IMPACT 2002+ provides a rough estimation of uncertainty on three scales (high, medium, and low) for the fate, exposure, and effect modelling for each impact category. Human toxicity (at midpoint level) and human health (endpoint level) are marked as "high" in uncertainty [26] in IMPACT 2002+. EDIP 2003 suggests using a site-dependent CF for those processes with the largest contribution to site-generic impacts, aiming to reduce the spatially determined uncertainty [28]. CML-IA points out several uncertainties related to embodying value choices and model structure; thus, sensitivity analysis is suggested by the method on different time horizons and spatial scales [29]. TRACI points out that it is important to understand the uncertainties in results associated with the underlying method, which can be achieved by consulting the original sources of the CFs [30,35]. 


\subsection{Methodology}

\subsubsection{Goal and Scope Definition}

This study follows the LCA methodological framework, which contains four main steps: goal and scope definition, life cycle inventory analysis, impact assessment, and interpretation. The goal of this study is to compare and examine different methods for assessing the life cycle impacts on human health in the context of biofuel supply chains, in order to empirically understand the effects of method selection on the assessment results, to identify the level of consensus among various LCIA methods, and to further provide insights into the potential impacts of biofuel production on human health.

The comparative analysis was conducted for the life cycle impacts of aviation biofuel on human health in the case of Brazil, a key player in global biofuel production. Based on recent literature on aviation biofuel, three feedstocks stand out in respects of techno-economic feasibility [11,42], environmental impacts (mainly GHG emissions reduction) [43], and socioeconomic impacts [44] for the Brazilian context. Therefore, we focused on three aviation biofuel alternatives produced from the feedstocks with corresponding conversion technologies that are suitable for each feedstock: (i) the sugarcane via alcohol to jet (ATJ) pathway, (ii) the eucalyptus via fast pyrolysis (FP) pathway, and (iii) the macauba via hydro-processed esters and fatty acids (HEFA) pathway. The LCA was performed on the basis of a functional unit of $1 \mathrm{MJ}$ aviation fuel, assuming the lower heating value (LHV) for fossil aviation fuel and aviation biofuel are $44.1 \mathrm{MJ} / \mathrm{kg}$ and $43.3 \mathrm{MJ} / \mathrm{kg}$, respectively $[6,8]$.

Figure 1 depicts the system boundaries, which cover feedstock production, biomass transport (to biorefinery), aviation biofuel production technology, biofuel distribution (from biorefinery to airports), and end use (i.e., combustion). The fields of sugarcane, eucalyptus, and macauba were assumed to be located in São Paulo, Minas Gerais, and Minas Gerais, respectively. The produced aviation biofuel was expected to be used in two major Brazilian airports: Guarulhos airport (in São Paulo) and Galeão airport (in Rio de Janeiro State). Fossil jet fuel production is considered as the reference system. Its inventories were analyzed for crude oil refining, transport and distribution, and combustion.

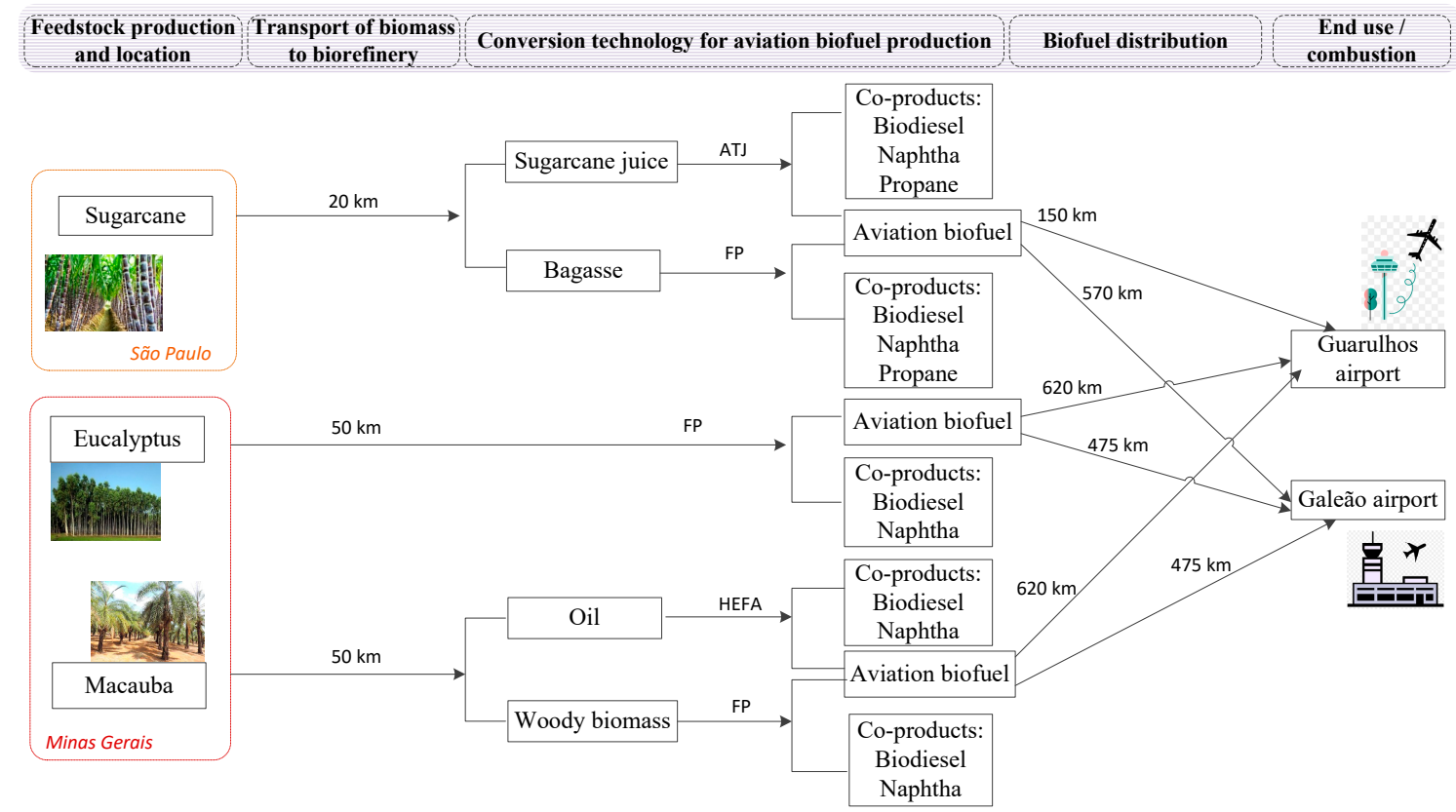

Figure 1. Scope of aviation biofuel supply chains for the comparative analysis of LCIA methods on human health-related impacts. 


\subsubsection{Life Cycle Inventory}

Inventories of Aviation Fuel Production

This study focuses on the construction of foreground processes inputs and outputs. Detailed inventory of foreground data can be found in Tables S1 and S2 in Supplementary Material. The background inventories were compiled with Simapro software using the Ecoinvent 3 database.

The practices of feedstock (i.e., sugarcane, eucalyptus, and macauba) cultivation and their related emissions are highly dependent on the locations and technologies available. Thus, data on emissions for feedstocks production were obtained from the most recent context-specific LCA/LCI studies of sugarcane production in Sao Paulo [44], average eucalyptus production (forest production subsystem) in Brazil [45,46], and macauba cultivation in Minas Gerais [47].

Aviation biofuel was considered to be obtained via different technologies in biorefineries. The Sugarcane-ATJ route mainly involves six processes: sugarcane milling, sugarcane juice fermentation, and ethanol upgrade to jet fuel (and co-products) via dehydration, oligomerization, and hydrogenation $[48,49]$. Furthermore, bagasse produced in the sugarcane milling process was also considered to be converted to aviation biofuel via the thermochemical process FP [50]. The eucalyptus-FP route contains two subsequent processes: (1) dried lignocellulosic feedstocks are converted at high temperatures (around $500{ }^{\circ} \mathrm{C}$ ) into bio-oil (Jones et al. 2013), and (2) bio-oil is subsequently converted into aviation biofuel (and co-products) via hydrogenation [50]. The macauba-HEFA route requires (1) oil extraction from seeds, (2) oil hydro-treatment for deoxygenation, and (3) isomerization and hydrocracking [51]. The rest of the macauba feedstock (woody biomass residue) was also considered to be converted to aviation biofuel via the FP process. Each of these three aviation biofuel routes generates co-products, namely biodiesel, naphtha, and propane. In addition, several auxiliary units producing heat/electricity (i.e., co-generation of steam and power (co-gen)), and hydrogen (via steam methane reforming (SMR)) were integrated in the biorefineries. A wastewater treatment plant (WWT) was also integrated for water reuse purpose.

Input data on biomass transport and biofuel distribution are adopted from the configuration design of aviation biofuel supply chains in Brazil by [8,42]. An average of $20 \mathrm{~km}, 50 \mathrm{~km}$, and $50 \mathrm{~km}$ was considered for transporting feedstocks from the fields to the biorefineries by heavy-duty trucks for the sugarcane-ATJ biofuel, eucalyptus-FP biofuel, and macauba-HEFA biofuel, respectively. The considered distribution distance of each biofuel to Guarulhos airport was $150 \mathrm{~km}, 620 \mathrm{~km}$, and $620 \mathrm{~km}$, respectively, and to Galeão airport was $570 \mathrm{~km}, 475 \mathrm{~km}$, and $475 \mathrm{~km}$, respectively.

So far, emissions data of aviation biofuel combustion have only been reported for HEFA and gasification Fischer-Tropsch (GFT) biofuels [6,52-54]. Here we drew on the same inventories of HEFA aviation biofuel combustion in the Regulated Emissions and Energy use in Transportation (GREET) tool [6] for all three aviation biofuels considered in our study, as the properties of aviation biofuels are similar by design and the majority of current commercial aviation biofuel is produced via HEFA. The inventories of fossil aviation fuel were derived from the GREET database [6], which enables the calculation of well-to-wake emissions of both fossil and biofuels.

\section{Allocation Method}

Allocation is commonly applied in LCA studies to empirically deal with co-products as they are produced along the processes. However, the way of handling co-products can have large effects on the results. Essentially, either system expansion or partitioning method is used to handle the allocation issue of multiple inputs and outputs of processes [55]. According to the International Standards Organization (ISO) 14,044 standard [56], the system expansion approach is preferable as it recognizes the mitigated emissions attributed to co-products. Nonetheless, system expansion requires defining production systems of the co-products (e.g., biodiesel), which, in reality, can be produced by different pathways. This adds to the overall uncertainty and complexity of the study. Therefore, the partitioning method seems to better fit the objective of this study. Allocation based on mass, energy, or economic 
values has been used in LCA studies of biofuel or bioenergy systems. Each allocation method has its own advantages and disadvantages. Mass allocation is based on the weight of main product and co-products, thus not applicable for co-products that cannot be measured by mass (such as electricity). Energy allocation is based on the energy content of product and co-products, which means that it is less suitable for non-energy co-products. Although economic allocation is suggested as the last resort by ISO standard, it is able to capture the competitiveness of products' market value [46]. For comparison purposes, this study applies mass, energy, and economic allocations, respectively, to distribute the emissions burden among all products of the aviation biofuel production process. The allocation factors used are presented in Table 2. In Section 3, the results and discussion presented are based on energy allocation as the main product and co-products are all energy products. Mass and economic allocations were used for sensitivity analysis.

Table 2. Allocation factors used for aviation biofuel and co-products (SC: sugarcane, EC: eucalyptus, and MC: macauba).

\begin{tabular}{|c|c|c|c|c|c|}
\hline \multirow{2}{*}{ Supply Chain } & \multirow{2}{*}{ Conversion Pathway } & \multirow{2}{*}{ Product Fraction } & \multicolumn{3}{|c|}{ Allocation Method } \\
\hline & & & Mass & Energy & Economic \\
\hline \multirow[t]{8}{*}{ SC-ATJ ${ }^{a}$} & Juice-ATJ & Jet fuel & 0.81 & 0.80 & 0.89 \\
\hline & & Diesel & 0.11 & 0.12 & 0.08 \\
\hline & & Naphtha & 0.03 & 0.03 & 0.02 \\
\hline & & Propane & 0.05 & 0.05 & 0.01 \\
\hline & Bagasse-FP & Jet fuel & 0.42 & 0.42 & 0.54 \\
\hline & & Diesel & 0.33 & 0.32 & 0.28 \\
\hline & & Naphtha & 0.19 & 0.20 & 0.16 \\
\hline & & Propane & 0.06 & 0.06 & 0.02 \\
\hline \multirow[t]{3}{*}{ EC-FP } & & Jet fuel & 0.41 & 0.40 & 0.52 \\
\hline & & Diesel & 0.37 & 0.37 & 0.30 \\
\hline & & Naphtha & 0.22 & 0.23 & 0.18 \\
\hline \multirow[t]{7}{*}{ MC-HEFA $^{b}$} & Oil-HEFA & Jet fuel & 0.55 & 0.54 & 0.69 \\
\hline & & Diesel & 0.26 & 0.26 & 0.21 \\
\hline & & Naphtha & 0.08 & 0.08 & 0.07 \\
\hline & & Propane & 0.11 & 0.12 & 0.03 \\
\hline & Woody biomass-FP & Jet fuel & 0.41 & 0.42 & 0.52 \\
\hline & & Diesel & 0.37 & 0.37 & 0.30 \\
\hline & & Naphtha & 0.22 & 0.21 & 0.18 \\
\hline
\end{tabular}

${ }^{a}$ After milling, sugarcane juice was converted to aviation biofuel via ATJ, while bagasse is also converted to aviation biofuel via FP. ${ }^{b}$ After oil extraction, macauba oil was converted aviation biofuel via HEFA while the rest parts of macauba feedstock (EFB, fronds, and trunks) were also converted to aviation biofuel via FP.

\subsubsection{Impact Assessment: Comparison among Different Methods}

It is challenging to compare the results in absolute values, as these LCIA methods vary in multiple aspects. Thus, we performed a contribution analysis $[18,57,58]$ for the results calculated with different methods. This means comparing (1) the relative ranking of human health impacts of different aviation biofuel alternatives, and (2) the percentages of impacts that different life cycle stages, processes, and substances account for. The life cycle human health impacts of aviation biofuels were analyzed and compared using the LCA software tool Simapro@, which integrates all the above discussed methods and allows a comparative contribution analysis at the life cycle, process, and substance levels.

First, an overview is given for all relevant impact categories at midpoint and endpoint levels calculated with all methods. This step reveals the relative ranking (in \%) of the aviation biofuel alternatives based on each human health LCIA method: the impacts of the worst alternative would be marked as $100 \%$, whereas the impacts of other alternatives would be less than $100 \%$. 
Secondly, a qualitative comparison was conducted between fossil jet fuel and each of the aviation biofuel alternatives in respect to each impact on human health that are comparable. Here, we intended to determine whether the biofuels outperform fossil fuel. Specifically, two loose tolerance ranges (rule of thumb) were considered for the qualitative comparison, namely $\pm 15 \%$ and $\pm 20 \%$. The rationale here is that given the potentially large and implicit uncertainty (while can be caused by model performance, data, and variability) in the calculated impacts on human health, the comparison between fossil fuel and aviation biofuel based on deterministic calculation can be indecisive. That is, it is not strictly clear which one performs better, especially when the differences in the deterministically calculated results are relatively small and might not be able to differentiate whether the alternative actually performs better. Thus, we drew on these two tolerance ranges $( \pm 15 \%$ and $\pm 20 \%)$ and considered biofuels perform "equally" well as the fossil-based fuel (reference system) when the differences in the concern impact categories are within $\pm 15 \%$ or $\pm 20 \%$.

Thirdly, we performed a contribution analysis for each impact category resulting from the comparable LCIA methods. This analysis compared how the individual life cycle stage and the process of each aviation biofuel supply chain contribute to each impact on human health. We aimed to identify similarities as well as differences among these three aviation biofuel alternatives based on these LCIA methods.

In order to be considered comparable, LCIA methods should include the same or equivalent impact category and have the same or similar definition for the impact category concerned. As described in Section 2, some impact categories are expressed in different names by different methods. Thus, for the sake of unity and simplicity, we use the terms "fine particulate matter (FPM)" and "photochemical smog (PS)" to represent the two impact categories named differently in ReCiPe 2016, IMPACT 2002+, and TRACI. Based on the comparison provided in Table 1, the following LCIA methods are considered comparable and their results are compared in Sections 3.2 and 3.3:

- For midpoint human carcinogenic toxicity (HCT): USEtox $2(r+i)($ Only USEtox $2(r+i)$ is included in the comparative analysis, as according to the developers of this method, practitioners should always use indicative $\mathrm{CFs}$ together with recommended CFs to calculate toxicity in empirical studies. Thus, USEtox 2 (r) is excluded.), ReCiPe 2016 (E) (ReCiPe 2016 (I) is excluded from the comparative analysis as its timeframe is 20 years, which is significantly shorter than the remaining methods.), ReCiPe 2016 (H), IMPACT 2002+, and TRACI;

- For midpoint human non-carcinogenic toxicity (HNCT): USEtox $2(r+i), \operatorname{ReCiPe} 2016$ (E), ReCiPe 2016 (H), IMPACT 2002+, and TRACI;

- For midpoint fine particulate matter (FPM): ReCiPe 2016 (E), ReCiPe 2016 (H), IMPACT 2002+, and TRACI;

- For midpoint photochemical smog (PS): ReCiPe 2016 (E), ReCiPe 2016 (H), IMPACT 2002+, and TRACI;

- $\quad$ For endpoint human health (HH): ReCiPe 2016 (E), ReCiPe 2016 (H), and IMPACT 2002+.

\section{Results and Discussion}

\subsection{Relative Ranking of Aviation Biofuel Alternatives}

Figure 2 gives an overview of all relevant impacts of the three aviation biofuel alternatives and fossil jet fuel on human health. Results are shown at both midpoint and endpoint levels. The majority of LCIA methods suggest that in respect to midpoint impacts, macauba-HEFA biofuel is associated with the lowest impacts while eucalyptus-FP is associated with the highest. In most cases, fossil jet fuel is associated with neither the highest nor the lowest midpoint impacts on human health. At midpoint level, there seems to be a high level of consensus between USEtox $2(\mathrm{r}+\mathrm{i}), \operatorname{ReCiPe} 2016(\mathrm{E}), \operatorname{ReCiPe}$ 2016 (H), TRACI, and CML-IA regarding human toxicity, despite some fluctuations. USEtox 2 (r) leads to different results than these four methods, as it only considers "recommended" CFs for calculating human toxicity. Consequently, the effects caused by toxic substances with "indicative" CFs are left 
out, meaning that the toxicity is essentially underestimated. Furthermore, ReCiPe 2016 (I) results in a different relative ranking, as it reflects the value perspective of an "individualist" - in which case a timeframe of 20 years is considered for effect modelling. This is considerably shorter than that of the remaining methods (i.e., 100 years or infinite). Additionally, IMPACT 2002+ is a European method whereas the rest of the methods are global (regarding the default $\mathrm{CFs}$ ). The spatial-temporal differences can be responsible for the large differences in the resulting relative ranking. Moreover, different methods lead to different FPM and ozone layer depletion (OLD) impacts due to geographic differences, whereas the resulting impacts on PS, ionizing radiations (IR), and global warming (GW) are highly consistent regardless of methods.

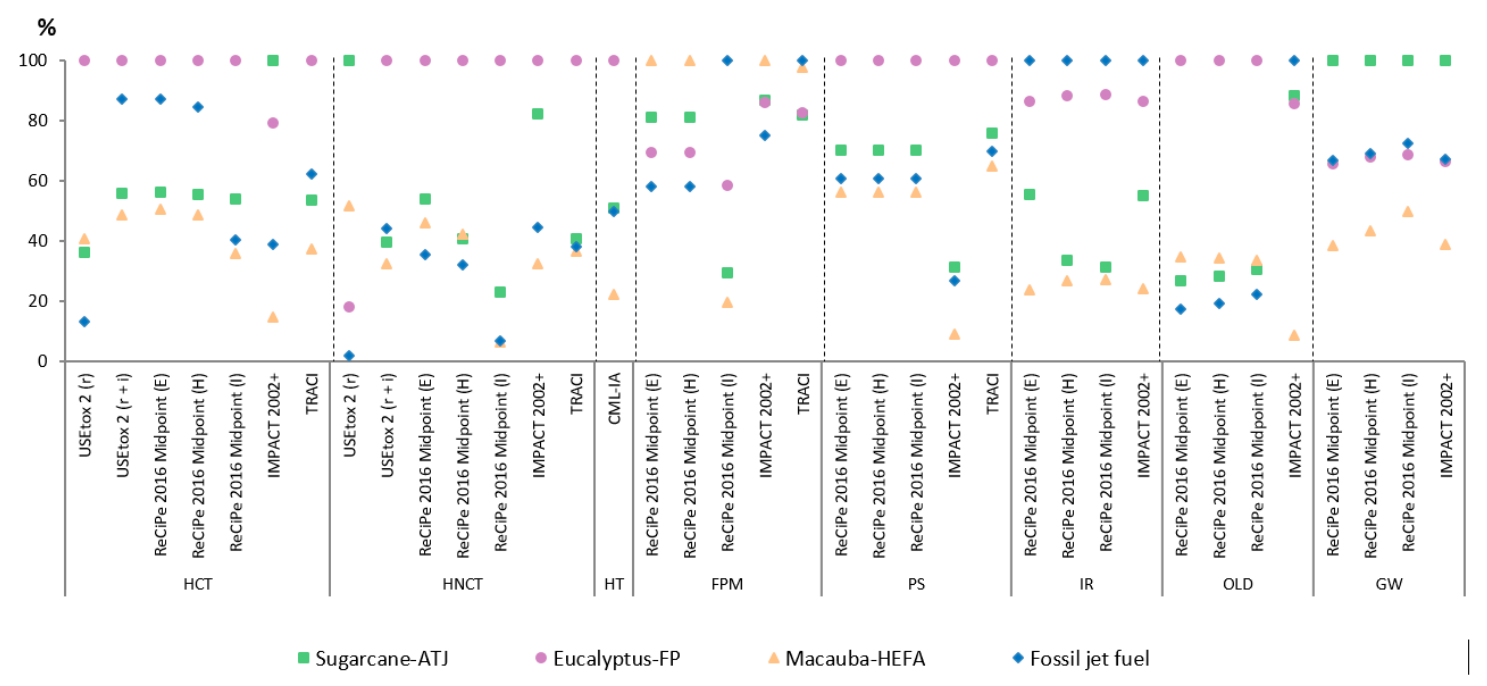

(a) Midpoint impacts

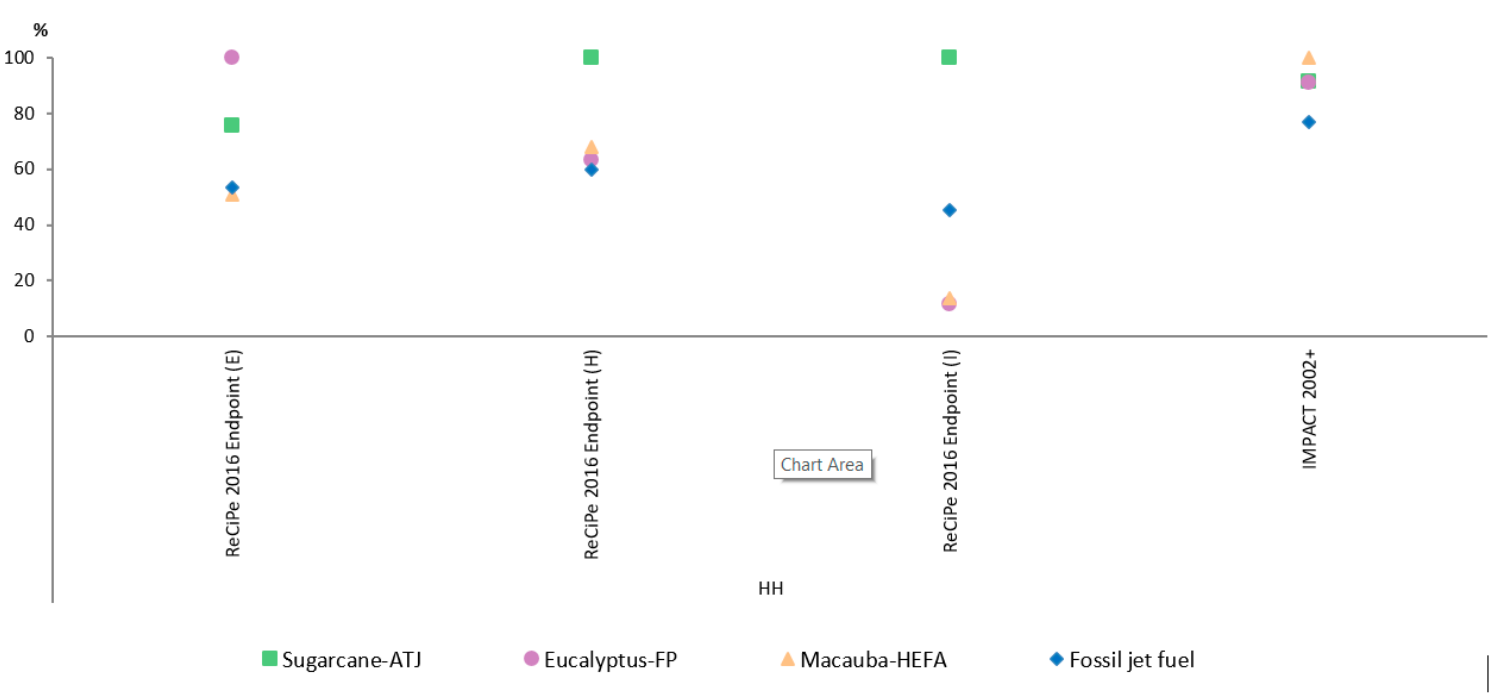

(b) Endpoint impacts

Figure 2. Life cycle midpoint (a) and endpoint (b) impacts of $1 \mathrm{~L}$ jet fuel, resulted from different LCIA methods (HCT: human carcinogenic toxicity, HNCT: human non-carcinogenic toxicity, FPM: fine particular matter, PS: Photochemical smog, IR: ionizing radiations, OLD: ozone layer depletion, GW: global warming, HT: human toxicity, HH: human health, HTP: human toxicity potential).

At endpoint level, the results are more scattered in terms of the relative ranking of these four fuels. This is mainly due to the differences in the definition and scope of the endpoint human health impact, 
including different geographical and temporal scales, different coverage of substances, difference input data, as well as different damage pathways in each method. For example, IMPACT 2002+ takes into account carcinogenic and non-carcinogenic toxicity, fine particulate matter, photochemical smog, ozone depletion, and ionizing radiation, when quantifying the damage to human health at the endpoint. In addition to all the impact pathways considered in IMPACT 2002+, ReCiPe 2016 also considers global warming as a potential cause of damage to human health.

\subsection{How do Aviation Biofuel Alternatives Perform Compared to Fossil Jet Fuel?}

Section 3.1 has demonstrated general trends of the relative ranking of the four jet fuels, calculated with different LCIA methods from a helicopter view. This section takes a closer look at the results, focusing on the LCIA methods that are comparable, intending to answer the question "do these methods agree with each other on whether biofuels outperform fossil fuel and (if yes) what do they agree on?"

As shown in Figure 3, the qualitative comparison shows that aviation biofuels do not always lead to lower impacts on human health. In terms of HCT, all methods suggest that macauba-HEFA biofuel always performs better than fossil jet fuel, while the eucalyptus-FP biofuel performs no better than fossil fuel, regardless of the tolerance range. With respect to HNCT, all the methods agree that sugarcane-ATJ biofuel performs no better than fossil fuels, whereas eucalyptus-FP biofuel always performs worse than fossil fuels, despite the tolerance range. Regarding FPM, all the methods agree that macauba-HEFA biofuel performs no better than its fossil counterpart, despite the tolerance range. With a $\pm 20 \%$ tolerance range, all methods show that eucalyptus-FP biofuel performs equivalently to fossil fuels in respect to FPM. Furthermore, PS receives the highest level of consensus among different methods. In this regard, the sugarcane-ATJ and the macauba-HEFA biofuels perform no worse than fossil fuel while the eucalyptus-FP biofuel always performs worse than fossil fuel, in spite of the tolerance range. On the other hand, all methods agree that all three biofuel alternatives perform no better than fossil fuel in respect of $\mathrm{HH}$ at endpoint, regardless of the tolerance range.

It is worth noting that, with a $\pm 15 \%$ tolerance range, sugarcane-ATJ biofuel performs worse than fossil fuel in terms of PS, with the exception of TRACI. However, when expanding the tolerance range to $\pm 20 \%$, all methods show that sugarcane-ATJ biofuel always performs as well as fossil fuels. This indicates that uncertainties in the calculated results play an important part and can essentially affect interpretation.

On the other hand, LCIA methods do not agree on how well aviation biofuels perform in respects to HCT and FPM of sugarcane-ATJ biofuel, HNCT of macauba-HEFA biofuel, and FPM $( \pm 15 \%)$ of eucalyptus-FP biofuel. This can be explained by the differences in geographic scope, substance coverage, toxicity data, and modelling choices-in addition to uncertainties in effect modelling between IMPACT 2002+, TRACI, ReCiPe 2016, and USEtox 2.

\subsection{Contribution Analysis}

\subsubsection{Human Carcinogenic and Non-Carcinogenic Toxicity}

As shown in Figure 4, USEtox $2(\mathrm{r}+\mathrm{i})$, ReCiPe 2016 (E), ReCiPe $2016(\mathrm{H})$, and TRACI result in similar process contributions in respects to HCT and HNCT for all fuels. This is because these are all global methods and (partially or entirely) rely on the USEtox 2 substance database, which is also why IMPACT 2002+ does not share the consensus among the other four methods. 


$$
\begin{array}{ll}
\text { (a) } \pm 15 \% & \text { SC-ATJ } \\
& \text { EC-FP }
\end{array}
$$$$
\begin{array}{l|lllll}
\text { MC-HEFA } & & & & & \\
& U(r+i) & R(E) & R(H) & I M & T R
\end{array}
$$

HCT

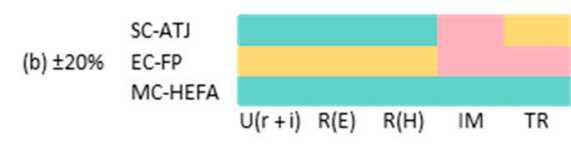

HCT

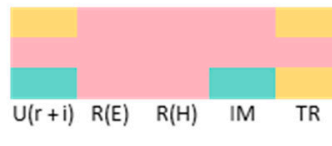

HNCT

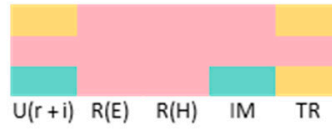

HNCT

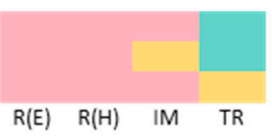

FPM

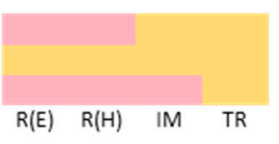

FPM

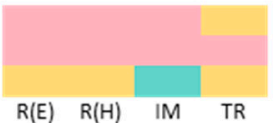

PS

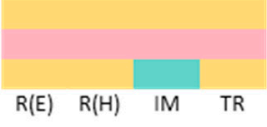

PS

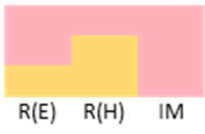

$\mathrm{HH}$

$R(E) \quad R(H) \quad I M$

$\mathrm{HH}$

Figure 3. Color matrices illustrating the qualitative comparison between aviation biofuels and fossil jet fuel with regard to each impact category (HCT: human carcinogenic toxicity, HNCT: human non-carcinogenic toxicity, FPM: fine particular matter, PS: Photochemical smog, HH: human health; U ( $r+i)$ : USEtox 2 ( $r+i)$, R (E): ReCiPe (E), R (H): ReCiPe (H), IM: IMPACT2002+, TR: TRACI), considering tolerance ranges of (a) $\pm 15 \%$ and (b) $\pm 20 \%$. 
HCT

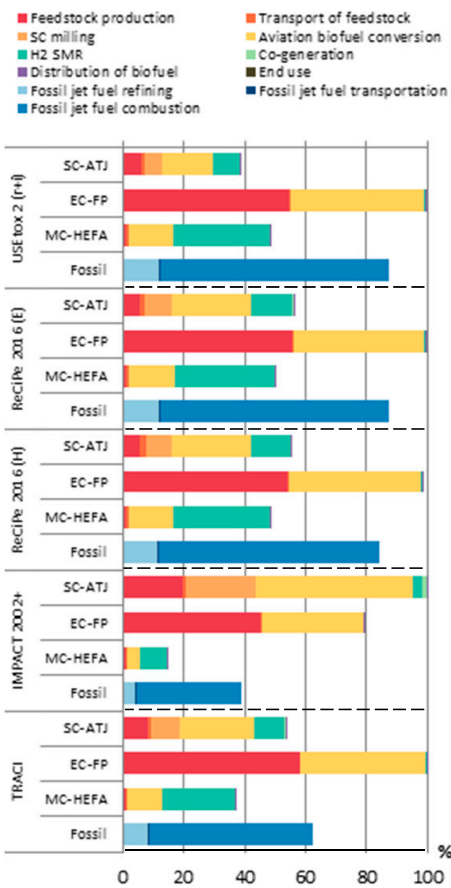

HNCT

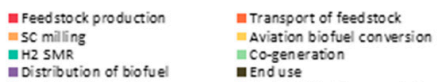

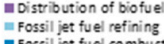$$
\text { SCAAT } \mid
$$

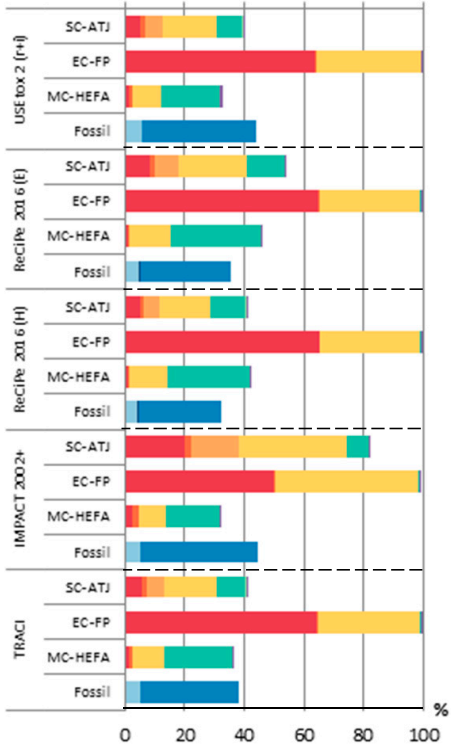

FPM

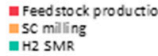

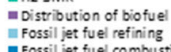

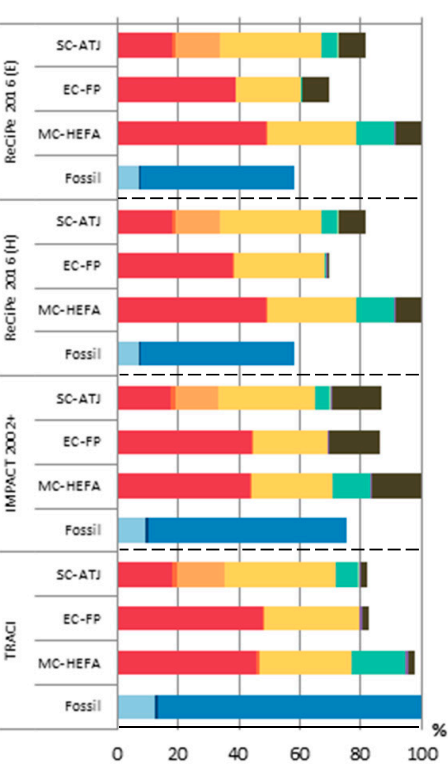

PS MTransport of feedstock
Naviation bif fuel con version

End use

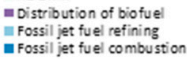

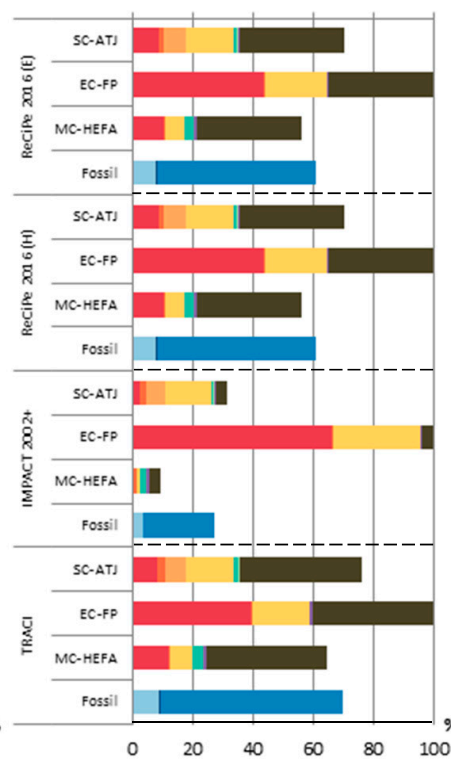

$\mathrm{HH}$

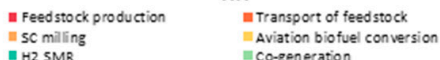
EEnduse "ivosil jet tuel refining $\quad$ Fossil jet fuel transportation

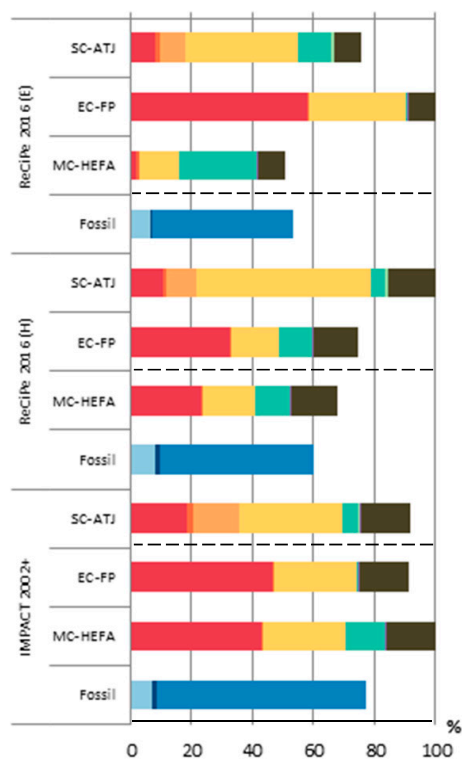

Figure 4. Contribution analysis for each impact category (HCT: human carcinogenic toxicity, HNCT: human non-carcinogenic toxicity, FPM: fine particular matter, PS: Photochemical smog, HH: human health). 
Despite this disagreement, all methods suggest that biofuel conversion and the production of $\mathrm{H} 2$ are the main contributors to HCT and HNCT of all three aviation biofuels. This means that industrial processing accounts for $41-95 \%$ HCT and 34-92\% HNCT of aviation biofuel production.

\subsubsection{Fine Particulate Matter}

A general agreement is seen in FPM resulting from different methods, with the exception of some fluctuations in the results calculated for the end use stage of aviation biofuels. According to all methods, FPM is predominantly caused by biofuel conversion and feedstock production, which are responsible for $27-45 \%$ and $20-58 \%$ of this impact, respectively. The contributions of biofuels' end use calculated with IMPACT 2002+ is the largest, followed by ReCiPe 2016 (E) and ReCiPe $2016(\mathrm{H})$, while TRACI allocates the smallest impacts to end use. The minor differences in results here can again be attributed to the differences in geographic specification, database, and model specification among these LCIA methods.

\subsubsection{Photochemical Smog}

PS resulting from ReCiPe 2016 (E), ReCiPe 2016 (H), and TRACI leads to highly similar results: the end use stage of aviation biofuels is the predominant contributor, which accounts for $35-62 \%$ of this effect. In comparison, IMPACT 2002+ results in significantly lower effects for the end use of biofuels, which is responsible for only $4-40 \%$ of the life cycle PS impact. The large differences here can be explained by the differences in the definition and scope of this impacts. Specifically, IMPACT 2002+ considers this impact as the respiratory effects from organics [34]; ReCiPe 2016 considers effects caused by ozone formed as a result of photochemical reactions of NOx and non-methane volatile organic compounds (NMVOCs) [25]; and TRACI considers effects caused by ground level ozone created by chemical reactions, which occur between NOx and volatile organic compounds (VOCs) in sunlight [30].

\subsubsection{Human Health}

At the endpoint level, LCIA methods agree that biofuel conversion is an important contributor (25-57\%) to HH. It is worth noting that although ReCiPe 2016 (E) and ReCiPe 2016 (H) lead to very similar results in respects to HCT, HNCT, FMP, and PS, they show different results in HH. This is because the ReCiPe 2016 method also models damage to human health caused by additional impacts, such as ionizing radiation, ozone layer depletion, and global warming [25]. Despite the similarities shared by the "egalitarian" and the "hierarchist" perspectives in HCT, HNCT, FMP, and PS, differences do exist regarding other impacts, leading to different human health impacts at the endpoint level.

In addition, feedstock production in the eucalyptus-FP supply chain is another key contributor to all $\mathrm{HH}$ impacts-accounting for $54-58 \%$ of HCT, $50-65 \%$ of HNCT, $51-58 \%$ of FPM, $39-66 \%$ of PS, and $51-60 \%$ of $\mathrm{HH}$ in this particular supply chain. As reported in the literature [46], fertilizers used in eucalyptus cultivation are highly relevant to human toxicity and ecotoxicity.

\subsubsection{Fossil Jet Fuel}

The life cycle contribution analysis for fossil jet fuel seems highly consistent among all methods. All methods show the combustion of fossil jet fuel is the single predominant contributor (more than $80 \%$ ) to life cycle HCT, HNCT, FPM, PS, and HH, followed by a significantly lower share of fuel refining whereas the contribution of transport and distribution is insignificant. The production system of fossil jet fuel is considerably more mature and standardized than that of the burgeoning aviation biofuel. Therefore, the life cycle impacts-including life cycle human health impacts of the fossil supply chain—are better captured and more consistently represented in different LCIA methods [15]. 


\subsection{Sensitivity Analysis}

As indicated in Section 2, that the allocation of emissions to main product and co-products can have large effects on results, and in Section 3.2, that biofuel conversion is the key contributor to all human health impacts, we conducted a sensitivity analysis on the allocation method and biofuel conversion yield. In comparison to energy allocation, we calculated each impact based on economic allocation and mass allocation, using the allocation factors shown in Section 2.2. To explore the effect of biofuel conversion yield on the resulting human health impacts, we considered a pessimistic yield and an optimistic yield for each aviation biofuel alternative, based on energy allocation. The values of these two yields were derived from literature, as shown in Table 3.

Table 3. Sensitivity analysis ranges of biofuel conversion yields.

\begin{tabular}{cccccc}
\hline \multirow{2}{*}{ Supply Chain } & \multirow{2}{*}{ Unit } & \multicolumn{3}{c}{ Yield } & \multirow{2}{*}{ Reference } \\
\cline { 3 - 5 } & & Pessimistic & Base & Optimistic & \\
\hline SC-ATJ & kg biofuel/kg sugarcane, & 0.81 & 0.80 & 0.89 & {$[8]$} \\
EC-FP & kg biofuel/kg woody biomass & 0.41 & 0.40 & 0.52 & {$[16,42]$} \\
MC-HEFA & kg biofuel/kg pulp oil & 0.55 & 0.54 & 0.69 & {$[16,42]$} \\
\hline
\end{tabular}

Both economic and mass allocations assign larger effects to aviation biofuels for each impact category (Figure 5). Specifically, economic allocation results in a variation of $1.66-8.54 \%, 5.75-14.38 \%$, and $2.99-8.08 \%$ in all impact categories for sugarcane-ATJ, eucalyptus-FP, and macauba-HEFA biofuels, respectively. Mass allocation, in comparison, leads to considerably lower variation $(<2 \%)$ in all aviation biofuel alternatives, due to similar allocation factors in energy allocation. With the pessimistic conversion yield, these human health impacts in sugarcane-ATJ, eucalyptus-FP, and macauba-HEFA biofuels would increase by $0.96-2.64 \%, 1.20-2.03 \%$, and $0.08-2.12 \%$, respectively. On the other hand, the optimistic conversion yield would lower these impacts by $0.86-6.75 \%, 5.70-9.59 \%$, and $0.23-8.27 \%$, for sugarcane-ATJ, eucalyptus-FP, and macauba-HEFA biofuels, respectively.

Overall, the variations due to different allocation methods or biofuel conversion yields are moderate $(< \pm 15 \%)$, whereas the eucalyptus-FP aviation biofuel supply chain is the most sensitive to the changes of variables for all impact categories.

\subsection{Improvement Opportunities for Aviation Biofuel Alternatives}

Despite the discrepancy among the human health impacts resulting from different LCIA methods, the conversion of biofuel is the common hotspot for all three aviation biofuels (as shown in Section 3.3) - which is primarily a result of the use of toxic chemicals, the use of primary energy, and the disposal of wastes (the substance contribution analysis for each aviation biofuel alternative can be found in the Supplementary Material). It is, therefore, recommended to focus on the research and development of more efficient and cleaner aviation biofuel pathways that require fewer toxic chemicals or replace them entirely. $\mathrm{H} 2$ is an indispensable input for all aviation biofuel conversion pathways. However, H2 SMR using natural gas is a major source of human health impacts. Other alternative processes, such as gasification of biomass or electrolysis [6,23], are alternatives to avoid the use of primary energy. In addition, the introduction of more stringent waste management practices to deal with waste disposal would also contribute to reducing life cycle impacts on human health. For instance, ash from the thermochemical degradation of biomass can be used as fertilizer in agriculture, which can potentially reduce the fertilizer needs in fields [46,59-61]. Nevertheless, the feasibility of this option depends on the content of minerals and heavy metals in the ash, as well as local regulations on the use of biomass ash in agriculture [19]. 


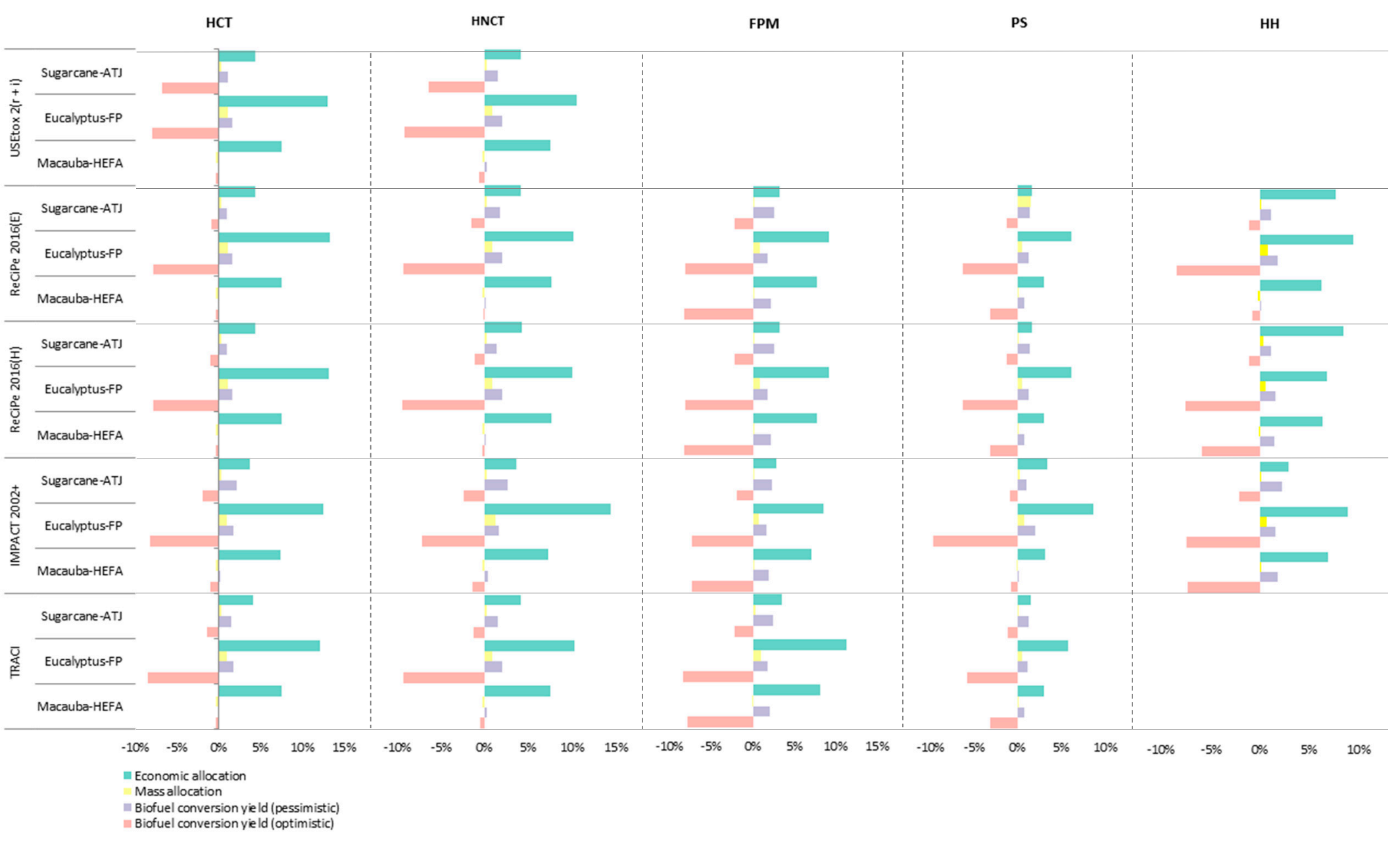

Figure 5. Sensitivity analysis on the allocation method (i.e., economic allocation and mass allocation) and biofuel conversion yield (i.e., pessimistic and optimistic), expressed in change in \%, using energy allocation as the base case. 
Another key contributor to the life cycle human health impacts is feedstock production, which is mainly caused by using fertilizers and pesticides. This calls for attention to cultivation practice improvement, especially in fertilizer and pesticide management. On the one hand, technological advancement in species selection would potentially increase yield, thereby reducing the total demand of agrichemicals. On the other hand, the development of more efficient fertilizer and pesticide application techniques (e.g., optimizing the timing and placement of fertilizers, and improving the accuracy of nutrient needs prediction) would potentially improve the efficacy of the application of agrichemicals $[17,61]$. Additionally, given that the combustion of aviation biofuel has a large impact on respiratory effects (FPM and PS), improvements in aircraft engines to increase efficiency are required in order to help reduce related effects.

\subsection{Lessons Learned for Selecting LCIA Methods for Human Health Assessment}

Although different LCIA methods lead to distinct results of life cycle impacts on human health, we were able to identify some general trends and consensus among these methods. While it may still remain challenging to draw a consensual conclusion on which method is the best, lessons can be learned with regard to the choice and application of LCIA methods for assessing human health in the context of biofuel supply chains.

Apparently, there is no single one-size-fits-all method here. In an LCA study, the first step of goal and scope definition determines the features of the study on a macro level. If the geographical specification plays an important role, then IMPACT 2002+, TRACI, USEtox 2, and EDIP 2003 might be favored, as they feature specific regions. Furthermore, if the LCA study addresses certain value perspectives in particular, ReCiPe 2016 can shape the assessment in accordance with a specific value preference.

Focusing on the aviation biofuel supply chains in our case study, biofuel conversion is the primary contributor to all impacts. Thus, it is necessary to choose a method that includes the characterization of all inputs in industrial processes. Feedstock production is another significant contributor of aviation biofuel supply chains, especially eucalyptus-FP biofuel. The health effects related to the heavy metals in fertilizers are associated with high uncertainty $[16,18]$. Hence, the differences in the characterization modelling of metals are important sources of discrepancy. Furthermore, it is also important to consider the impact categories of interest. As the combustion of aviation biofuels results in considerable respiratory effects, it seems evident that the impacts on human health would be underestimated if only USEtox 2 were chosen. Hence, many factors need to be considered when making decisions on which method is the most appropriate.

Given that the USEtox 2 method was developed based on scientific consensus, it is intuitive to use this method as the reference method for assessing life cycle human health impacts. In fact, there has been a trend that a number of LCIA methods (e.g., ReCiPe 2016, TRACI, and CML-IA) have started to adopt the USEtox 2 substance database for calculating human health effects. However, the characterization of human health effects among these methods still differs, due to embedded differences in their own characterization models. This is why the results calculated with these methods still vary largely in some cases.

In line with the above discussed factors, the ReCiPe 2016 model appears to be a well-rounded method for assessing the life cycle human health impacts of aviation biofuel supply chains, as it (i) includes assessment of both human toxicity and respiratory effects, (ii) provides CFs for a large number of substances, and (iii) is (partially) based on the consensus model USEtox 2.

Nevertheless, the choice of methods for assessing health effects should be made case by case, depending on each specific context. Therefore, we provide a self-check list below for LCA practitioners to choose the method that best suits their LCA study.

1. What are the spatial, temporal, and value choice specifications of the LCA study?

2. What is the preferred level of impact assessment (midpoint or endpoint)?

3. Which human health impact categories are of interest? 
4. Which method(s) include as many CFs as possible for assessing all input substances?

5. Are there any environmental compartments and exposure pathways of particular interest?

6. What can be the potential "hotspots" of the LCA study?

7. Which method(s) include as many CFs as possible for assessing potential "hotspots"?

8. If multiple methods appear suitable, do they lead to consistent results? If not, a sensitivity analysis is recommended to provide insights into the differences.

A decision tree is shown in Figure 6, which exemplifies how to use these self-check questions to determine the most appropriate LCIA method(s) for assessing human health impacts. This example demonstrates various options based on the first three questions. These are the fundamental questions for a life cycle human health assessment study to start with. At this point, a preliminary screening of suitable LCIA methods should be achieved. Furthermore, the LCA practitioner is recommended to continue with decision making based on the remaining questions and possible additional questions related to goal definition. It is also recommended to first compare results from different potentially suitable methods (based on the preliminary screening) to identify potential "hotspots", and subsequently decide on the most appropriate method based on how these "hotspots" are assessed in each individual method, as listed in Questions 6-8.
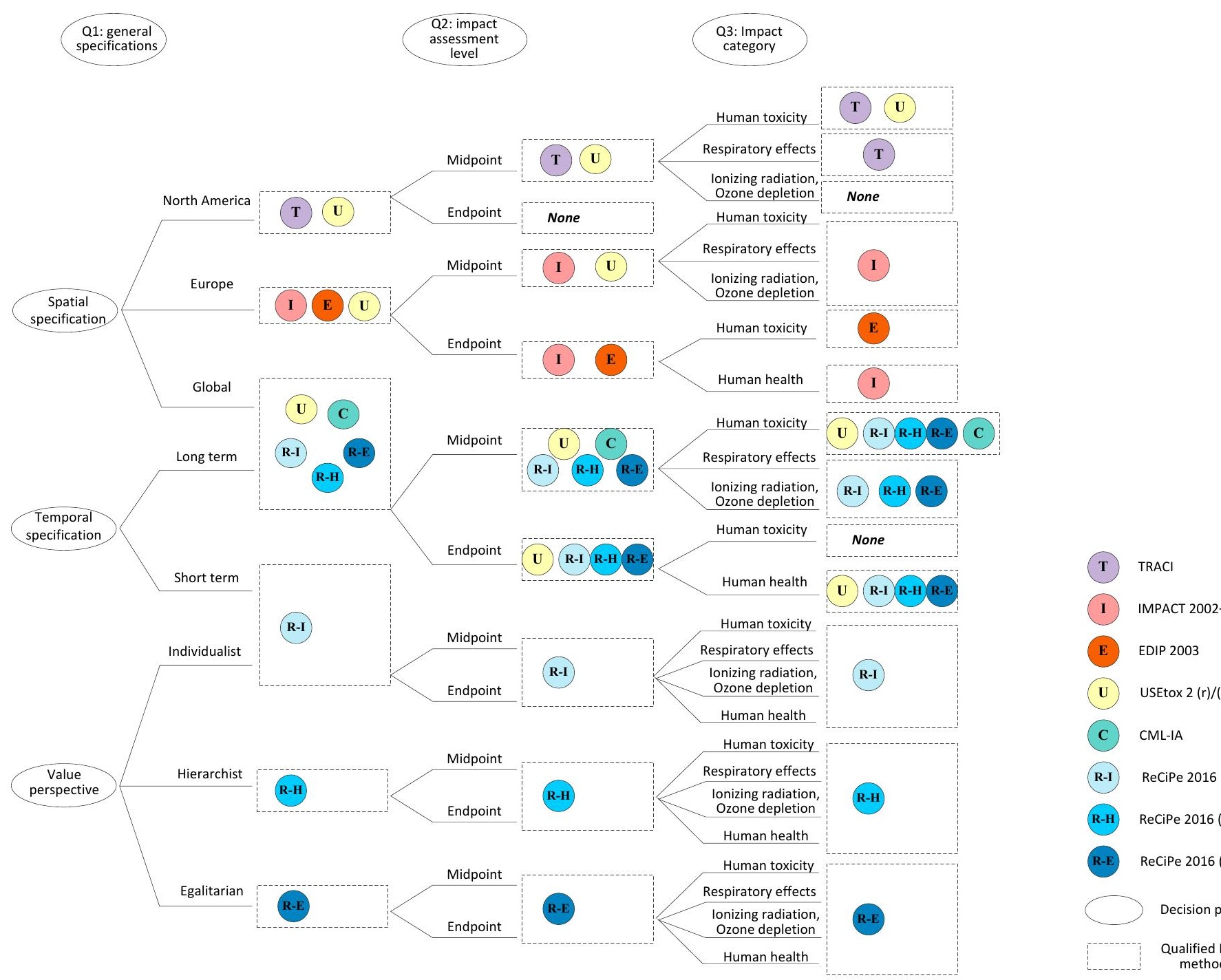

Figure 6. Schematic presentation of an example of the decision tree to identify the appropriate LCIA method(s). 


\section{Conclusions}

This study aimed to provide a systematic comparison among six common LCIA methods for quantifying human health impacts, namely USEtox 2, ReCiPe 2016, IMPACT 2002+, EDIP 2003, CML-AI, and TRACI, in the context of biofuel supply chains. The comparative analysis was performed for the production of three distinct aviation biofuels in Brazil: sugarcane-ATJ, eucalyptus-FP, and macauba-HEFA biofuels; and the potential human health impacts were assessed for five life cycle impact indicators: HCT, HNCT, FPM, PS, and HH. Although these LCIA methods differ from each other in multiple aspects, the majority of them reveal that macauba-HEFA biofuel is associated with the lowest impacts, and eucalyptus-FP biofuel with the highest, with respect to HCT, HNCT, FPM, and PS. That is, aviation biofuels do not always lead to better life cycle human health impacts than fossil jet fuels. In particular, aviation biofuels tend to outperform their fossil counterpart with regard to HCT, while performing equivalently or worse regarding the remaining human health impacts.

Overall, biomass conversion into aviation biofuel is a major contributor to all impact categories; namely HCT (by 28-52\%), HNCT (by 19-45\%), FPM (by 27-45\%), PS (by 12-48\%), and HH (by 25-57\%), resulting from the three aviation biofuels, regardless of LCIA methods. Feedstock production also accounts for large effects in respect to FPM (20-56\%), whereas the end use of aviation biofuel leads to a significant PS impact (4-62\%). To reduce the impact of aviation biofuels on human health, it is worth considering the development of cleaner biofuel conversion technologies that require fewer toxic chemicals or avoid them altogether, that use sustainably produced $\mathrm{H} 2$, and that encourage more stringent waste management practices. Additionally, improvements in feedstock cultivation practices, biofuel conversion yield, and aircraft engine efficiency can also contribute towards mitigating the impacts on human health.

There is no one-size-fits-all LCIA method for assessing human health impacts, and the choice of methods should be made case-by-case, depending on the specific context. In this regard, we have provided some general guidelines consisting of a list of self-check questions for LCA practitioners to determine an appropriate method for the assessment of human health impacts.

Supplementary Materials: The following are available online at http://www.mdpi.com/2227-9717/8/2/158/s1, Table S1: Life cycle inventory for the feedstock production phase, based on the functional unit of $1 \mathrm{~L}$ jet fuel, Table S2: Life cycle inventory for the industrial production phase, based on the functional unit of $1 \mathrm{~L}$ jet fuel, Table S3: Top 20 substance contribution (in \%) to HCT, resulting from different LCIA methods, Table S4: Top 20 substance contribution HNCT, resulting from different LCIA methods, Table S5: Top 10 substance contribution FPM, resulting from different LCIA methods, Table S6: Top 20 substance contribution PS, resulting from different LCIA methods, Table S7: Top 20 substance contribution HH, resulting from different LCIA methods.

Author Contributions: Conceptualization, Z.W. and J.A.P.; methodology, Z.W. and J.A.P.; software, Z.W.; formal analysis, Z.W.; writing-original draft preparation, Z.W.; writing-review and editing, Z.W., J.A.P. and P.O.; visualization, Z.W.; supervision, J.A.P. and P.O.; project administration, J.A.P. and P.O. All authors have read and agreed to the published version of the manuscript.

Funding: This work is carried out within the BE-Basic R\&D Program, which was granted a FES subsidy from the Dutch Ministry of Economic Affairs.

Conflicts of Interest: The authors declare no conflict of interest.

\section{References}

1. International Air Transport Association (IATA). 2014. IATA 2015 Report on Alternative Fuels. Available online: https://www.iata.org/publications/Documents/2015-report-alternative-fuels.pdf (accessed on 10 March 2019).

2. International Civil Aviation Organization (ICAO). 2016. Resolution A39-3: Consolidated Statement of Continuing ICAO Policies and Practices Related to Environmental Protection-Climate Hange (39th General Assembly). Available online: https://www.icao.int/environmental-protection/Documents/Resolution_A39_3. pdf (accessed on 3 May 2019).

3. Bailis, R.E.; Baka, J.E. Greenhouse gas emissions and land use change from Jatropha curcas-based jet fuel in Brazil. Environ. Sci. Technol. 2010, 44, 8684-8691. [CrossRef] 
4. Cox, K.; Renouf, M.; Dargan, A.; Turner, C.; Klein-Marcuschamer, D. Environmental life cycle assessment (LCA) of aviation biofuel from microalgae, Pongamia pinnata, and sugarcane molasses. Biofuels Bioprod. Biorefin. 2014, 8, 579-593. [CrossRef]

5. de Jong, S.; Antonissen, K.; Hoefnagels, R.; Lonza, L.; Wang, M.; Faaij, A.; Junginger, M. Life-cycle analysis of greenhouse gas emissions from renewable jet fuel production. Biotechnol. Biofuels 2017, 10, 64. [CrossRef]

6. Elgowainy, A.; Han, J.; Wang, M.; Carter, N.; Stratton, R.; Hileman, J.; Malwitz, A.; Balasubramanian, S. Life-Cycle Analysis of Alternative Aviation Fuels in GREET (No. ANL/ESD/12-8); Argonne National Laboratory: Oak Ridge, TN, USA, 2012.

7. Han, J.; Elgowainy, A.; Cai, H.; Wang, M.Q. Life-cycle analysis of bio-based aviation fuels. Bioresour. Technol. 2013, 150, 447-456. [CrossRef]

8. Santos, C.I.; Silva, C.C.; Mussatto, S.I.; Osseweijer, P.; van der Wielen, L.A.; Posada, J.A. Integrated 1st and 2nd generation sugarcane bio-refinery for jet fuel production in Brazil: Techno-economic and greenhouse gas emissions assessment. Renew. Energy 2017, 129, 733-747. [CrossRef]

9. Shonnard, D.R.; Williams, L.; Kalnes, T.N. Camelina-derived jet fuel and diesel: Sustainable advanced biofuels. Environ. Prog. Sustain. 2010, 29, 382-392. [CrossRef]

10. Staples, M.D.; Malina, R.; Olcay, H.; Pearlson, M.N.; Hileman, J.I.; Boies, A.; Barrett, S.R. Lifecycle greenhouse gas footprint and minimum selling price of renewable diesel and jet fuel from fermentation and advanced fermentation production technologies. Energy Environ. Sci. 2014, 7, 1545-1554. [CrossRef]

11. Prussi, M.; O'Connell, A.; Lonza, L. Analysis of current aviation biofuel technical production potential in EU28. Biomass Bioenergy 2019, 130, 105371. [CrossRef]

12. Chuck, C. (Ed.) Biofuels for Aviation: Feedstocks, Technology and Implementation; Academic Press: Cambridge, MA, USA, 2016; ISBN 978-0-12-804568-8.

13. Crossin, E.M. Aviation Biofuels Life Cycle Assessment; RMIT University: Melbourne, Australia, 2014.

14. Kim, S.; Dale, B.E. Life cycle assessment of fuel ethanol derived from corn grain via dry milling. Bioresour. Technol. 2008, 99, 5250-5260. [CrossRef]

15. Tsang, M.; Fox-Lent, C.; Wallace, S.; Welp, T.; Bates, M.; Linkov, I. Life-cycle impacts of soybean and algae biodiesel: Case study of US marine vessels. Biofuels Bioprod. Biorefin. 2015, 9, 567-580. [CrossRef]

16. de Jong, S.; Hoefnagels, R.; Faaij, A.; Slade, R.; Mawhood, R.; Junginger, M. The feasibility of short-term production strategies for renewable jet fuels-A comprehensive techno-economic comparison. Biofuels Bioprod. Biorefin. 2015, 9, 778-800. [CrossRef]

17. Yang, Y. Life cycle freshwater ecotoxicity, human health cancer, and noncancer impacts of corn ethanol and gasoline in the US. J. Clean. Prod. 2013, 53, 149-157. [CrossRef]

18. Yang, Y.; Bae, J.; Kim, J.; Suh, S. Replacing gasoline with corn ethanol results in significant environmental problem-shifting. Environ. Sci. Technol. 2012, 46, 3671-3678. [CrossRef]

19. Pizzol, M.; Christensen, P.; Schmidt, J.; Thomsen, M. Impacts of "metals" on human health: A comparison between nine different methodologies for Life Cycle Impact Assessment (LCIA). J. Clean. Prod. 2011, 19, 646-656. [CrossRef]

20. Rosenbaum, R.K.; Bachmann, T.M.; Gold, L.S.; Huijbregts, M.A.; Jolliet, O.; Juraske, R.; Koehler, A.; Larsen, H.F.; MacLeod, M.; Margni, M.; et al. USEtox-The UNEP-SETAC toxicity model: Recommended characterisation factors for human toxicity and freshwater ecotoxicity in life cycle impact assessment. Int. J. Life Cycle Assess. 2008, 13, 532. [CrossRef]

21. Weldu, Y.W.; Assefa, G.; Jolliet, O. Life cycle human health and ecotoxicological impacts assessment of electricity production from wood biomass compared to coal fuel. Appl. Energy 2017, 187, 564-574. [CrossRef]

22. Galdos, M.; Cavalett, O.; Seabra, J.E.; Nogueira, L.A.; Bonomi, A. Trends in global warming and human health impacts related to Brazilian sugarcane ethanol production considering black carbon emissions. Appl. Energy 2013, 104, 576-582. [CrossRef]

23. Parada, M.P.; Osseweijer, P.; Duque, J.A. Sustainable biorefineries, an analysis of practices for incorporating sustainability in biorefinery design. Ind. Crops Prod. 2017, 106, 105-123. [CrossRef]

24. Hauschild, M.Z.; Huijbregts, M.; Jolliet, O.; MacLeod, M.; Margni, M.; van de Meent, D.; Rosenbaum, R.K.; McKone, T.E. Building a model based on scientific consensus for life cycle impact assessment of chemicals: The search for harmony and parsimony. Environ. Sci. Technol. 2008, 42, 7032-7037. [CrossRef] 
25. Huijbregts, M.A.J.; Steinmann, Z.J.N.; Elshout, P.M.F.; Stam, G.; Verones, F.; Vieira, M.D.M.; Hollander, A.; Zijp, M.; van Zelm, R. ReCiPe 2016: A Harmonized Life Cycle Impact Assessment Method at Midpoint and Endpoint Level Report I: Characterization. Rijksinstituut voor Volksgezondheid en Milieu RIVM. Available online: https://rivm.openrepository.com/handle/10029/620793 (accessed on 21 March 2019).

26. Jolliet, O.; Margni, M.; Charles, R.; Humbert, S.; Payet, J.; Rebitzer, G.; Rosenbaum, R. IMPACT 2002+: A new life cycle impact assessment methodology. Int. J. Life Cycle Assess. 2003, 8, 324. [CrossRef]

27. Hauschild, M. Spatial differentiation in life cycle impact assessment: A decade of method development to increase the environmental realism of LCIA. Int. J. Life Cycle Assess. 2006, 11, 11-13. [CrossRef]

28. Hauschild, M.; Potting, J. Spatial Differentiation in Life Cycle Impact Assessment-The EDIP2003 Methodology; Institute for Product Development, Technical University of Denmark: Miljøstyrelsen Copenhagen, Denmark, 2005.

29. Guinée, J.B. Handbook on life cycle assessment operational guide to the ISO standards. Int. J. Life Cycle Assess. 2002, 7, 311-313. [CrossRef]

30. Bare, J.; Young, D.; Qam, S.; Hopton, M.; Chief, S. Tool for the Reduction and Assessment of Chemical and other Environmental Impacts (TRACI); US Environmental Protection Agency: Washington, DC, USA, 2012.

31. Hauschild, M.; Goedkoop, M.; Guinée, J.; Heijungs, R.; Huijbregts, M.A.J.; Jolliet, O.; De Schryver, A. Recommendations for Life Cycle Impact Assessment in the European Context-Based on Existing Environmental Impact Assessment Models and Factors; European Commission-DG Joint Research Centre, JRC: Publications Office of the European Union: Luxembourg, 2011. Available online: http://ct.jrc.ec.europa.eu/assessment/projects (accessed on 26 October 2018).

32. Fantke, P. UNEP/SETAC Scientific Consensus Model for Characterizing Human Toxicological and Ecotoxicological Impacts of Chemical Emissions in Life Cycle Assessment; USEtox®International Center Hosted at the Technical University of Denmark: Lyngby, Demark, 2017.

33. Huijbregts, M.A.; Steinmann, Z.J.; Elshout, P.M.; Stam, G.; Verones, F.; Vieira, M.; Zijp, M.; Hollander, A.; van Zelm, R. ReCiPe2016: A harmonised life cycle impact assessment method at midpoint and endpoint level. Int. J. Life Cycle Assess. 2017, 22, 138-147. [CrossRef]

34. Humbert, S.; De Schryver, A.; Bengoa, X.; Margni, M.; Jolliet, O. IMPACT 2002+: User Guide, 2012.

35. van Zelm, R.; Huijbregts, M.A.; van de Meent, D. USES-LCA 2.0—A global nested multi-media fate, exposure, and effects model. Int. J. Life Cycle Assess. 2009, 14, 282. [CrossRef]

36. Goedkoop, M.J. The Eco-Indicator 99 a Damage Oriented Method for Life Cycle Impact Assessment Methodology Report; Pre Concultants: Amersfoort, The Netherlands, 1999.

37. McKone, T.E. CalTOX, a Multimedia Total Exposure Model for Hazardous-Waste Sites; Lawrence Livermore National Lab.: Livermore, CA, USA, 1993.

38. Carter, W.P. Development of ozone reactivity scales for volatile organic compounds. Air Waste 1994, 44, 881-899. [CrossRef]

39. Carter, W.P. Development of the SAPRC-07 chemical mechanism. Atmos. Environ. 2010, 44, 5324-5335. [CrossRef]

40. Hauschild, M.Z.; Wenzel, H. Environmental Assessment of Products—Scientific Background; Kluwer Academic Publishers: London UK, 1998.

41. Wenzel, H.; Hauschild, M.Z.; Alting, L. Environmental Assessment of Products_Volume 1: Methodology, Tools and Case Studies in Product Development; Chapman \& Hall Publishers: London, UK, 1997.

42. Alves, C.M.; Valk, M.; de Jong, S.; Bonomi, A.; van der Wielen, L.A.; Mussattom, S.I. Techno-economic assessment of biorefinery technologies for aviation biofuels supply chains in Brazil. Biofuels Bioprod. Biorefin. 2016, 11, 67-91. [CrossRef]

43. Wang, Z.; Kamali, F.P.; Osseweijer, P.; Posada, J.A. Socioeconomic effects of aviation biofuel production in Brazil: A scenarios-based Input-Output analysis. J. Clean. Prod. 2019, 230, 1036-1050. [CrossRef]

44. Maga, D.; Thonemann, N.; Hiebel, M.; Sebastião, D.; Lopes, T.F.; Fonseca, C.; Gírio, F. Comparative life cycle assessment of first-and second-generation ethanol from sugarcane in Brazil. Int. J. Life Cycle Assess. 2019, 24, 266-280. [CrossRef]

45. Saraiva, A.B.; Valle, R.A.; Bosque, A.E., Jr.; Berglin, N.; v Schenck, A. Provision of pulpwood and short rotation eucalyptus in Bahia, Brazil-Environmental impacts based on lifecycle assessment methodology. Biomass Bioenergy 2017, 105, 41-50. [CrossRef] 
46. Silva, D.A.; Pavan, A.L.; de Oliveira, J.A.; Ometto, A.R. Life cycle assessment of offset paper production in Brazil: Hotspots and cleaner production alternatives. J. Clean. Prod. 2015, 93, 222-233. [CrossRef]

47. Fernández-Coppel, I.A.; Barbosa-Evaristo, A.; Corrêa-Guimarães, A.; Martín-Gil, J.; Navas-Gracia, L.M.; Martín-Ramos, P. Life cycle analysis of macauba palm cultivation: A promising crop for biofuel production. Ind. Crops Prod. 2018, 125, 556-566. [CrossRef]

48. Atsonios, K.; Kougioumtzis, M.A.; Panopoulos, K.D.; Kakaras, E. Alternative thermochemical routes for aviation biofuels via alcohols synthesis: Process modeling, techno-economic assessment and comparison. Appl. Energy 2015, 138, 346-366. [CrossRef]

49. Wang, W.C.; Tao, L. Bio-jet fuel conversion technologies. Renew. Sustain. Energy Rev. 2016, 53, 801-822. [CrossRef]

50. Xu, X.; Zhang, C.; Liu, Y.; Zhai, Y.; Zhang, R. Two-step catalytic hydrodeoxygenation of fast pyrolysis oil to hydrocarbon liquid fuels. Chemosphere 2013, 93, 652-660. [CrossRef]

51. Pearlson, M.; Wollersheim, C.; Hileman, J.A. techno-economic review of hydroprocessed renewable esters and fatty acids for jet fuel production. Biofuels Bioprod. Biorefin. 2013, 7, 89-96. [CrossRef]

52. Bhagwan, R.; Habisreuther, P.; Zarzalis, N.; Turrini, F. An experimental comparison of the emissions characteristics of standard jet A-1 and synthetic fuels. Flow Turbul. Combust. 2014, 92, 865-884. [CrossRef]

53. Corporan, E.; Edwards, T.; Shafer, L.; DeWitt, M.J.; Klingshirn, C.; Zabarnick, S.; West, Z.; Striebich, R.; Graham, J.; Klein, J. Chemical, thermal stability, seal swell, and emissions studies of alternative jet fuels. Energy Fuels 2011, 25, 955-966. [CrossRef]

54. Stratton, R.W.; Wolfe, P.J.; Hileman, J.I. Impact of aviation non-CO2 combustion effects on the environmental feasibility of alternative jet fuels. Environ. Sci. Technol. 2011, 45, 10736-10743. [CrossRef]

55. Suh, S.; Weidema, B.; Schmidt, J.H.; Heijungs, R. Generalized make and use framework for allocation in life cycle assessment. J. Ind. Ecol. 2010, 14, 335-353. [CrossRef]

56. International Standards Organisation (ISO). Environmental Management. Life Cycle Assessment. Principles and Framework; ISO 14040:2006; ISO: Geneva, Switzerland, 2006.

57. Dreyer, L.C.; Niemann, A.L.; Hauschild, M.Z. Comparison of three different LCIA methods: EDIP97, CML2001 and Eco-indicator 99. Int. J. Life Cycle Assess. 2003, 8, 191-200. [CrossRef]

58. Gloria, T.; Russell, A.; Atherton, J.; Baker, S.; Cook, M. Ecological Toxicity Methods and Metals. An examination of two case studies (8 pp+1). Int. J. Life Cycle Assess. 2006, 11, 26-33. [CrossRef]

59. Khan, A.A.; de Jong, W.; Jansens, P.J.; Spliethoff, H. Biomass combustion in fluidized bed boilers: Potential problems and remedies. Fuel Process. Technol. 2009, 90, 21-50. [CrossRef]

60. James, A.; Thring, R.; Helle, S.; Ghuman, H. Ash management review-Applications of biomass bottom ash. Energies 2012, 5, 3856-3873. [CrossRef]

61. Robertson, G.P.; Vitousek, P.M. Nitrogen in agriculture: Balancing the cost of an essential resource. Annu. Rev. Environ. Resour. 2009, 34, 97-125. [CrossRef]

(C) 2020 by the authors. Licensee MDPI, Basel, Switzerland. This article is an open access article distributed under the terms and conditions of the Creative Commons Attribution (CC BY) license (http://creativecommons.org/licenses/by/4.0/). 